\title{
IMPROVED CATALYSTS FOR HEAVY OIL UPGRADING BASED ON ZEOLITE Y NANOPARTICLES ENCAPSULATED IN STABLE NANOPOROUS HOST
}

\author{
SIXTH SEMI-ANNUAL TECHNICAL PROGRESS REPORT
}

REPORT PERIOD: April 1, 2005-September 30, 2005

PRINCIPAL INVESTIGATOR: CONRAD INGRAM, Ph. D. Co. PI MARK MITCHELL, Ph. D.

REPORT DATE:

November 15, 2005

GRANT NUMBER:

DE- FG26-02NT41676

SUBMITTED TO:

U.S. Department of Energy

INSTITUTION:

CLARK ATLANTA UNIVERSITY 223 JAMES P. BRAWLEY DRIVE

ATLANTA, GA 30314 


\section{ABSTRACT}

Composite materials of SBA-15/zeolite Y were synthesized from zeolite Y precursor and a synthesis mixture of mesoporous silicate SBA-15 via a hydrothermal process in the presence of a slightly acidic media of $\mathrm{pH} 4-6$ with $2 \mathrm{M} \mathrm{H}_{2} \mathrm{SO}_{4}$. The SBA-15/ZY composites showed Type IV adsorption isotherms, narrow BJH average pore size distribution of $4.9 \mathrm{~nm}$, surface areas up to $800 \mathrm{~m}^{2} / \mathrm{g}$ and pore volumes $1.03 \mathrm{~cm}^{3}$, all comparable to pure SBA-15 synthesized under similar conditions. Chemical analysis revealed $\mathrm{Si} / \mathrm{Al}$ ratio down to 8.5 in the most aluminated sample, and ${ }^{27}$ AlSS MAS NMR confirmed aluminum was in tetrahedral coordination. This method of introduction of $\mathrm{Al}$ in pure $T_{d}$ coordination is effective in comparison to other direct and post synthesis alumination methods. Bronsted acid sites were evident from a pyridinium peak at 1544 $\mathrm{cm}^{-1}$ in the FTIR spectrum after pyridine adsorption, and from $\mathrm{NH}_{3}$-TPD experiments. SBA-15/ZY composites showed significant catalytic activities for the dealkylation of isopropylbenzene to benzene and propene, similar to those of commercial zeolite Y. It was observed that higher conversion for catalysts synthesized with high amount of ZY precursor mixture added to the SBA-15. Over all the composites has shown good catalytic activity. Further studies will be focused on gaining a better understand the nature of the precursor, and to characterize and to locate the acid sites in the composite material. The composite will also be evaluated for heavy oil conversion to naphtha and middle distillates. 


\section{DISCLAIMER}

This report was prepared as an account of work sponsored by an agency of the United Sates Government. Neither the United States Government nor any agency thereof, nor any of their employees, makes any warranty, express or implied, or assumes any legal liability or responsibility for the accuracy, completeness, or usefulness of any information, apparatus, product, or process disclosed, or represents that its use would not infringe privately owned rights. Reference herein, to any specific commercial product, process, or service by trade name, trademark, manufacturer or otherwise does not necessarily constitute or imply its endorsement, recommendation, or favoring by the United States Government or any agency thereof. The views and opinions of the authors expresses herein do not necessarily state or reflect those of the United States Government or any agency thereof. 


\section{EXECUTIVE SUMMARY}

The objective of this project is to synthesis nanocrystals of highly acidic zeolite Y, encapsulate them within the channels of mesoporous (nanoporous) silicates and evaluate the "zeolite Y/Nanoporous host" composites as catalysts for the upgrading of heavy petroleum feedstocks. In comparison to conventionally-used zeolite $\mathrm{Y}$ catalysts of micron size particles, the nanocrystals $(<100 \mathrm{~nm}$ particle size) which will contain shorter path lengths, will allow faster diffusion of large hydrocarbon substrates and the catalysis products within and out of the zeolite's channels and cages $(<1 \mathrm{~nm}$ size). This is expected to significantly reduce catalysts deactivation and prolong catalysts life. Encapsulating zeolite Y nanocrystals within the nanoporous materials will protect its external surfaces and pore entrances from being blocked by large hydrocarbon substrates, since these substrates will initially be converted to small molecules by the nanoporous host (a catalyst in its own right). The project consists of four major tasks as follows: a) synthesis of the nanoparticles of zeolite Y (of various chemical compositions) using various techniques such as the addition of organic additives to conventional zeolite $Y$ synthesis mixtures to suppress zeolite Y crystal growth; b) synthesis of nanoporous silicate host materials of up to $30 \mathrm{~nm}$ pore diameter. This was conducted using poly (alkylene oxide) copolymers as template around which inorganic silicate precursors are organized. Subsequently removal of the copolymer will yield a mesoporous material, the pore sizes of which will depend on the number of poly (alkylene oxide) units; (d) Synthesis of zeolite Y/Nanporous Host composite materials as potential catalysts and (d) catalysts evaluation for the upgrading of heavy petroleum feedstocks.

Our research activities for this reporting period is summarized as follows. Composite materials of SBA-15/zeolite $\mathrm{Y}$ were synthesized from zeolite $\mathrm{Y}$ precursor and a synthesis mixture of mesoporous silicate SBA-15 via a hydrothermal process in the presence of a slightly acidic media of $\mathrm{pH}$ 4-6 with $2 \mathrm{M} \mathrm{H}_{2} \mathrm{SO}_{4}$. The SBA-15/ZY composites showed Type IV adsorption isotherms, narrow BJH average pore size distribution of $4.9 \mathrm{~nm}$, surface areas up to $800 \mathrm{~m}^{2} / \mathrm{g}$ and pore volumes $1.03 \mathrm{~cm}^{3}$, all comparable to pure SBA-15 synthesized under similar conditions. Chemical analysis revealed $\mathrm{Si} / \mathrm{Al}$ ratio down to 8.5 in the most aluminated sample, and ${ }^{27} \mathrm{Al} \mathrm{SS}$ MAS NMR confirmed aluminum was in tetrahedral coordination. This method of introduction of Al in pure $T_{d}$ coordination is effective in comparison to other direct and post synthesis alumination methods. Bronsted acid sites were evident from a pyridinium peak at $1544 \mathrm{~cm}^{-1}$ in the FTIR spectrum after pyridine adsorption, and from $\mathrm{NH}_{3}-\mathrm{TPD}$ experiments. SBA-15/ZY composites showed significant catalytic activities for the dealkylation of isopropylbenzene to benzene and propene, similar to those of commercial zeolite Y. It was observed that higher conversion for catalysts synthesized with high amount of $\mathrm{ZY}$ precursor mixture added to the SBA-15. Over all the composites has shown good catalytic activity. Further studies will be focused on gaining a better understand the nature of the precursor, and to characterize and to locate the acid sites in the composite material. The composite will also be evaluated for heavy oil conversion to naphtha and middle distillates. 


\section{Table of Contents}

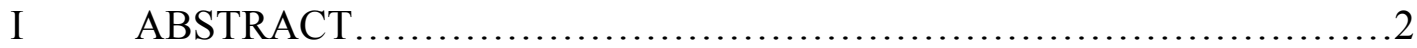

II. DISCLAIMER ....................................................

III EXECUTIVE SUMMARY ......................................4

IV INTRODUCTION .............................................. 6

$\mathrm{V} \quad$ BACKGROUND...................................................

VI EXPERIMENTAL SECTION .................................... 13

Materials $\quad$.................................................

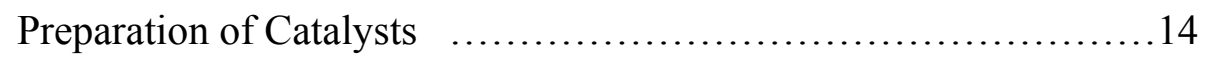

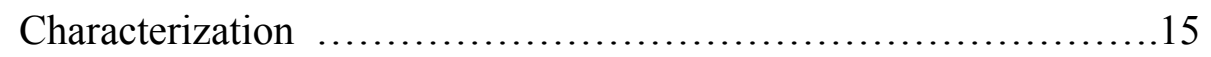

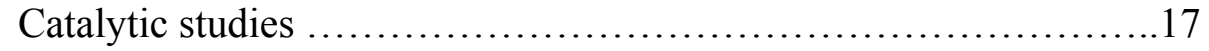

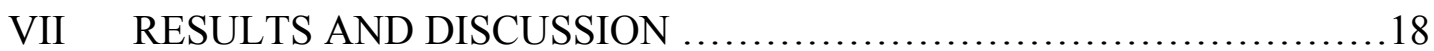

Porosity Characteristics of Fully Crystalline Zeolite Y Nanoparticles.........18

Synthesis of SBA-15/ZY Composites.................................18

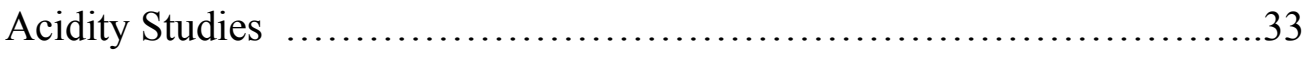

Catalysis....................................................... 35

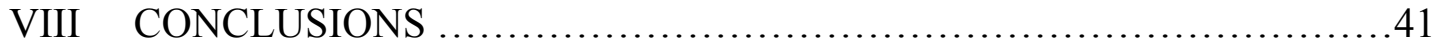

IX FUTURE WORK.............................................42

X TECHNOLOGY/INFORMATION TRANSFER ........................42

XI REFERENCES................................................43 


\section{INTRODUCTION}

The objective of this project is to synthesis nanocrystals/nanoblocks of highly acidic zeolite Y, encapsulate them within the channels of mesoporous (nanoporous) silicates or nanoporous organosilicates and evaluate the "zeolite Y/Nanoporous host" composites as catalysts for the upgrading of heavy petroleum feedstocks. In comparison to conventionally-used zeolite $\mathrm{Y}$ catalysts of micron size particles, the nanocrystals/nanoblock ( $<100 \mathrm{~nm}$ particle size) which will contain shorter path lengths, will allow faster diffusion of large hydrocarbon substrates and the catalysis products within and out of the zeolite's channels and cages $(<1 \mathrm{~nm}$ size $)$. This is expected to significantly reduce catalysts deactivation and prolong catalysts life. Encapsulating zeolite Y nanocrystals/nanoblocks within the nanoporous materials will protect its external surfaces and pore entrances from being blocked by large hydrocarbon substrates, since these substrates will initially be converted to small molecules by the nanoporous host (a catalyst in its own right). The project consists of four major tasks as follows: a) exploring the synthesis of the nanoparticles/nmanoblocks of zeolite Y (of various chemical compositions) using various techniques such as the addition of organic additives to conventional zeolite $\mathrm{Y}$ synthesis mixtures to suppress zeolite $\mathrm{Y}$ crystal growth; b) synthesis of nanoporous silicate host materials of up to $30 \mathrm{~nm}$ pore diameter. This was conducted using poly (alkylene oxide) copolymers as template around which inorganic silicate precursors are organized. Subsequently removal of the copolymer will

yield a mesoporous material, the pore sizes of which depended on the number of poly (alkylene oxide) units; (d) Synthesis of zeolite Y/Nanoporous Host composite materials as potential catalysts, and (d) Catalysts evaluation for the upgrading of heavy petroleum feedstocks.

In previous reports we presented the synthesis of high surface ordered nanoporous silica of expanded pore diameter of $25 \mathrm{~nm}$ (larger than the standard size of $8.4 \mathrm{~nm}$ ) using 
trimethylbenzene as a pore size expander was accomplished. The synthesis of zeolite $\mathrm{Y}$ nanoparticles with median pore size of approximately $50 \mathrm{~nm}$ (smaller than the $80 \mathrm{~nm}$ typically obtained with $\mathrm{TMAOH}$ ) using combined $\mathrm{TMABr} / \mathrm{TMAOH}$ as organic additives was also accomplished. The successful synthesis of zeoliteY/Nanoporous host composite materials by sequential combination of zeolite $\mathrm{Y}$ precursor mixtures and nanoporous material precursor mixtures was also suggested from results from various characterization techniques such as X-Ray diffraction, infrared spectra, thermal analysis, porosimetry data. In this report, we communicate the synthesis of improved SBA-15/ZY composites containing high surface areas and pore volumes. We also communicate the catalysts performance of the composites in acid catalyzed cumene de-alkylation as a probe reaction. Work in the immediate future will be focused on investigating the materials for the conversion of gas heavy gas oil.

\section{BACKGROUND}

The ever increasing demand for transportation fuel in the US requires that refineries improve their petroleum processing efficiency to increase the yield from hydrocracking of more refractory crude petroleum feedstocks, and effective catalysts are needed to achieve this. Characteristics needed for good catalysts include high specific surface area, high thermal stability, large pore volume, narrow pore size distribution and good accessibility to catalytic sites. ${ }^{11}$ In petroleum hydrocracking microporous aluminosilicate, zeolite catalysts (pore size $<0.8 \mathrm{~nm}$ ) have been providing vastly superior combinations of strong acid catalytic sites, uniformity of pore structure and stability, all of which provide improved selectivity, yield, durability, and cost over non-zeolite alternatives. Numerically, zeolites have provided much higher yield of gasoline and other high-quality fuels per barrel of crude oil, significantly reducing crude oil. As a result hydrocracking grew rapidly since the 1960s inside the US and worldwide hydrocracking capacity has 
grown from approximately 2.5 million barrels per day in 1990 to approximately 3.5 million in $2000{ }^{2}$

However, zeolites suffer rapid deactivation in the pressure of the hydrocracking process due to pore blockage from larger refractory substrates in petroleum feedstocks. There is a significant demand therefore for catalysts with enlarged pore diameters in the mesoporous range $(2-50 \mathrm{~nm})$. In search for alternative and more durable catalysts, the discovery of the new class of silica-based mesoporous materials by researchers of Mobil Company in 1992 has boosted a worldwide interest in this field. ${ }^{3}$ These materials are characterized by large pore size diameters that can be adjusted in the wide range between $1.5 \mathrm{~nm}$ and $10 \mathrm{~nm}^{4}$ One member of this series (MCM-41) possesses a regular hexagonal array of uniform and one-dimensional mesopores.

Following MCM-41, well-ordered hexagonal mesoporous silica SBA-15, was synthesized with pore size range from 2 to $30 \mathrm{~nm} .{ }^{5}$ SBA-15 has potential advantages over MCM-41 such as large pore size and thicker pore walls and hence high thermal stability. It was designed as potential catalyst for the processing of bulky molecules. However these catalytic expectations were not met because of its low thermal/hydrothermal stability, lack of acidity and well-defined active sites that are important in many catalytic processes. ${ }^{6,7}$ Beside its large uniform pore size (up to $30 \mathrm{~nm}$ ), SBA-15 has thicker walls than MCM-41, resulting in much higher stability. However, incorporation of aluminum into its siliceous framework by direct synthesis seems unlikely, because it is synthesized in strong acid media $(2 \mathrm{M} \mathrm{HCl})$ and most aluminum sources dissolve under these conditions.

SBA-15 is a mesoporous all silica material with a regular hexagonal pore arrangement and amorphous silica walls between the pores. SBA-15 exhibited a wall thickness of (3 - 
$7 \mathrm{~nm})$, large surface area $\left(900-1000 \mathrm{~m}^{2} / \mathrm{g}\right)$, pore volume $\left(1-1.26 \mathrm{~cm}^{3} / \mathrm{g}\right)$ and with crystallographic structure of $p 6 m m .^{8}$ The thick wall of SBA-15 imparted significantly greater hydrothermal stability in comparison to conventional MCM-41. SBA-15 can survive in boiling water for $24 \mathrm{~h}$ or calcinations at $550^{\circ} \mathrm{C}$, without structural degradation.

Unlike MCM-41 mesostructures, which are assembled under basic $\mathrm{pH}$ conditions compatible with proto-zeolitic seeds formation, SBA-15 mesostructures require strongly acidic reaction conditions for assembly that may not be so favorable for the incorporation of zeolitic subunits into the framework walls. The incorporation of aluminum into the frameworks of mesoporous molecular sieves has been investigated by researchers. Starting with Al-MCM-41 it was found that aluminum could be effectively incorporated into the mesoporous framework without serious structural deformation by direct synthesis, but the resulting acid sites were found to be weak .,10,11

Aluminosilicate mesostructures with wormhole framework structures were also assembled from proto-zeolitic nanoclusters (zeolite seeds) that normally nucleate the crystallization of faujasite (FAU), zeolite ZSM-5 (MFI) and zeolite Beta (BEA) in neutral media using non-ionic surfactant. ${ }^{12}$ The resulting aluminosilicate mesostructures exhibited high textural porosity and hydrothermal stability. However, product obtained showed low surface area, pore size and volume, low acidity for catalytic cumene conversion. 
The hydrothermal stability and acidity of Al-MCM-41 mesostructures were improved through the use of proto-zeolitic aluminosilicate nanoclusters or "zeolite seeds" as framework precursors. These nanoclusters contain the secondary building blocks of the zeolite structures that they nucleate. The first demonstration of this approach was to synthesize stable aluminosilicate mesostructures ${ }^{13}$ utilizing faujasitic zeolite seeds (FAU 0.74 nm) to construct the walls of a well ordered hexagonal MCM-41 structure. More recently, seeds from the highly acidic ZSM-5 (MFI $\sim 0.52 \mathrm{~nm}$ pore size) and zeolite beta $(\mathrm{BEA} \sim 0.56)^{14,15}$ have been used to assemble steam-stable Al- MCM-41 derivatives containing the five-ring subunits of these five membered ring zeolites. Due to the presence of microporous components, the acidity of microporous zeolitemesostructure composites was improved. ${ }^{16,17}$ A composite mixture of nanosized zeolite beta in a large-pore microporous material characterized by three sets of mutually perpendicular channels that is promising for a variety of catalytic processes. ${ }^{18,19}$ Materials showed ordered mesoporosity and zeolite beta microporosity where prepared as thin layers .

For SBA-15 using secondary methods to introduce Al is attractive since the highly acidic synthesis medium is not favorable. Yue et al. reported the direct synthesis of Al-SBA-15 by direct synthesis and investigated the hydrothermal stability and acidity of the product. The resulting Al-SBA-15 had large surface areas, good pore sizes and pore volumes. 
However, the method was not successful in placing aluminum in totally tetrahedral $\left(\mathrm{T}_{\mathrm{d}}\right)$ sites, since $\mathrm{Al}$ was found in both tetrahedral and octahedral coordination environments. ${ }^{20}$

To over come the challenges of direct synthesis researchers have investigated post synthesis modification. Sumiya et al. for example, reported the post synthesis incorporation of aluminum in siliceous SBA-15 structure using tetramethylammonium aluminum to produce AlSBA-15. Though, the Brönsted acid sites generated were reportedly stronger than those of AlMCM-41 prepared by the same method, the resulting surface areas of the calcined materials were low $\left(<400 \mathrm{~m}^{2} / \mathrm{g}\right)$. In addition it was difficult to keep the aluminum atoms in the tetrahedral framework coordination after calcinations, and extra-framework octahedrally coordinated aluminum species were formed. ${ }^{21}$ In an effort to incorporate stable aluminum within the structure of SBA-15, the possibility of using zeolite Y precursor (seeds) was investigated by Pinnavia and coworkers ${ }^{22,23}$. Though the resulting material was shown to have increased steam stability compared to the parent SBA-15, the surface was much lower than SBA- $15\left(<650 \mathrm{~cm}^{3} / \mathrm{g}\right)$. The effects of zeolite Y precursor concentration and aging time, and physicochemical characteristics of the materials, including pore size architectures, extent of structural ordering, acidity characteristics, aluminum content and catalytic characteristics, were not presented.

In an effort to assemble steam stable framework structures with pore sizes substantially larger than those provided by MCM-41, the possibility of using zeolite seeds to assemble 
SBA-15 have been examined. ${ }^{24,25}$ Unlike MCM-41 mesostructures, which are assembled under basic $\mathrm{pH}$ conditions, compatible with protozeolitic seeds formation, SBA-15 mesostructures requires strongly acidic reaction conditions for assembly that may not be so favorable for the incorporation of zeolitic subunits into the framework walls. ${ }^{26}$

For SBA-15 using secondary methods to introduce Al is attractive, since the highly acidic synthesis medium is not favorable. Yue et al. reported the direct synthesis of Al Al-SBA15 and investigated the hydrothermal stability and acidity of the product. The resulting Al-SBA-15 had large surface areas, good pore sizes and pore volumes. However, the method was not successful in placing aluminum in total tetrahedral environment, since $\mathrm{Al}$ was found in both tetrahedral and octahedral coordination. ${ }^{27}$

To overcome the challenges of aluminum incorporated by direct synthesis, researchers have investigated the techniques of post synthesis modification. For example Sumiya et $a l$, tried to incorporate aluminum in mesoporous SBA-15 by post-synthesis mechanism. The product well resolved peaks of XRD, confirming the well ordered structure of SBA15. The product also had with good pore volume $\left(1.3 \mathrm{~cm}^{3} / \mathrm{g}\right)$ and pore diameter $(8 \mathrm{~nm})$. However, the surface areas obtained were low $\left(<400 \mathrm{~m}^{2} / \mathrm{g}\right)$ and the aluminum framework in the material shows both tetrahedral and octahedral phases. ${ }^{28}$

Various research groups have been tried different methods to introduce Al into mesoporous channel of SBA-15 through direct and post synthesis methods. However, the 
material synthesized were having different problems such as low surface area, pore size and pore volume. It is also suffering from low acid sites and catalytic activity. The Al coordination of the composite material found both as tetrahedral and octahedral type with extra frame work.

The focus of this project will be to improve the catalytic activity of the composite material of SBA-15/ZY material and to successfully incorporate Al from zeolite Y precursor into the mesoporous SBA-15 through direct method. The material anticipated to have a good surface area, catalytic activity and tetrahedral coordinated Al with no extra-frameworks.

\section{Experimental Section}

Materials. Tetramethylammonium hydroxide $\left[\left(\mathrm{CH}_{3}\right)_{4} \mathrm{NOH}, \mathrm{TMAOH}, 25 \mathrm{wt} \%\right.$ in water, Aldrich Chemical Co.], aluminum isopropoxide $\left[\left(\mathrm{CH}_{3}\right)_{2} \mathrm{CHO}\right)_{3} \mathrm{Al}, 98 \%$ Aldrich Chemical Co.], sodium hydroxide [NaOH, Fischer Scientific], tetraethyl orthosilicates $\left[\left(\mathrm{C}_{2} \mathrm{H}_{5} \mathrm{O}\right)_{4} \mathrm{Si}\right.$, TEOS, Fischer Scientific $]$, Pluronic P-123 $\left[\left(\mathrm{EO}_{20} \mathrm{PO}_{70} \mathrm{EO}_{20}, \mathrm{MW}\right.\right.$ av $=$ 5800),BASF company], 1,3,5-trimethylbenzene $\left[\mathrm{C}_{9} \mathrm{H}_{12}, \mathrm{TMB}\right.$, mesitylene, $98 \%$ Aldrich Chemical Co.], tetramethylammonium bromide $\left[\mathrm{C}_{4} \mathrm{H}_{12} \mathrm{NBr}\right.$,TMABr, 98\% SigmaAldrich Chemical Co.], hydrochloric acid [HCl, 37.2\% Fischer Scientific] sulfuric acid $\left[\mathrm{H}_{2} \mathrm{SO}_{4}, 98 \%\right.$ Fischer Scientific] tetrapropyl ammonium hydroxide [TPAOH, Aldrich], sodium silicate $\left[\mathrm{NaSiO}_{2}\right.$ Aldrich],sodium aluminate $\left[\mathrm{NaAlO}_{2}\right.$, Sterm $\mathrm{Co}$.] Ammonium 
nitrate $\left[\mathrm{NH}_{4} \mathrm{NO}_{3}\right.$, Fischer Scientific], isopropyl benzene[ $\mathrm{C}_{9} \mathrm{H}_{12}$, Cumene, $98 \%$ Aldrich Chemical Co.], ethyl alcohol $\left[\mathrm{C}_{2} \mathrm{H}_{6} \mathrm{O}\right.$, ethanol Fischer Scientific].

Preparation of Catalysts: The synthesis of zeolite/SBA-15 composites were conducted in two steps. First the zeolite $\mathrm{Y}$ precursor was made and subsequent modified by the addition of SBA-15 components and reaction conditions. To form the precursor, typically $76.5 \mathrm{~g}$ of DDI water, $52.3 \mathrm{~g}$ of TMAOH, $17.0 \mathrm{~g}$ of TMABr $12.5 \mathrm{~g}$ of $\left[\left(\mathrm{CH}_{3}\right)_{2} \mathrm{CHO}\right)_{3} \mathrm{Al}$, $0.60 \mathrm{~g}$ of $\mathrm{NaOH}$ and $27 \mathrm{~g}$ of TEOS were mixed for 3 days at room temperature. The Si:Al ratio was calculated as 5:1. Conversion to SBA-15 was according to the following procedure. The mixture was diluted to $\mathrm{Si}: \mathrm{Al}$ ratio 50 , by mixing $20 \mathrm{~g}$ of precursor mixed with $40 \mathrm{~g}$ of TEOS and then heated at $100{ }^{\circ} \mathrm{C}$ for $12 \mathrm{hr}$. A $15.5 \mathrm{~g}$ aliquot of the dilute precursor was added to $4.5 \mathrm{gm}$ of $\mathrm{P}-123$, and $98.8 \mathrm{~g}$ of water. The $\mathrm{pH}$ of the mixture was adjusted 4-6 with $2 \mathrm{M} \mathrm{H}_{2} \mathrm{SO}_{4}$ and the mixture stirred for $12 \mathrm{~h}$ at $40-60{ }^{\circ} \mathrm{C}$. The final mixture of molar composition $1 \mathrm{SiO}_{2}: 0.01 \mathrm{Al}_{2} \mathrm{O}_{3}: 0.013 \quad \mathrm{P}-123: \mathrm{H}_{2} \mathrm{SO}_{4}: 70 \mathrm{H}_{2} \mathrm{O}$, was heated at $100^{\circ} \mathrm{C}$ for $24 \mathrm{~h}$ and the sample filtered, dried and calcined at $550^{\circ} \mathrm{C}$ dry flowing air at $70 \mathrm{ml} / \mathrm{min}$ for up to $14 \mathrm{~h}$. Purely siliceous SBA-15 was synthesized using the same procedure but in the absence of zeolite Y precursor. To verify that the precursor does yield zeolite $\mathrm{Y}$, aliquots of the former was allowed to crystallised for up to 4 days at $100^{\circ} \mathrm{C}$. The nanoparticles containing solid product was recovered using a Beckman J2-21 high-speed centrifuge at $15000 \mathrm{~g}$ for 40 minutes. Prior to catalysts evaluation, the calcined materials were refluxed with $0.5 \mathrm{M} \mathrm{NH}_{4} \mathrm{NO}_{3}(100 \mathrm{ml} / \mathrm{g})$ in at $70{ }^{\circ} \mathrm{C}$ for $6 \mathrm{hr}$. The 
solid was filtered, washed, dried and calcined at $550{ }^{\circ} \mathrm{C}$ for $5 \mathrm{~h}$. The samples were refluxed twice.

Characterization. Powder X-ray Diffraction (XRD) patterns were collected using a Philips X'PERT diffractometer with $\mathrm{CuK} \alpha(\lambda=0.154 \mathrm{~nm})$ radiation at $40 \mathrm{KV}$ and $45 \mathrm{~mA}$. Diffractograms were recorded from 1 to $10^{\circ}$ with a $2 \theta$ step size of $0.02^{\circ}$, a step time of 10 $\mathrm{s}$ and fixed divergent slit width of $0.5 \mathrm{~mm}$. Surface areas and nitrogen adsorptiondesorption isotherms were measured at 77K on a Micromeritics ASPS 2010 analyzer. The samples were degassed for $2 \mathrm{hr}$ at $200{ }^{\circ} \mathrm{C}$ under vacuum in the degassing port of the analyzer. Surface area was calculated using the BET model. Dynamic Light Scattering (DLS) analysis was performed on LB-550 Horiba Instrument. A dilute transparent sample was placed in a cuvette and placed in the incident beam of the instrument. Thermogravimetric analysis (TGA) analysis was performed on a SDT 2960 from TA instruments Inc. Milligram quantities of sample were placed in a platinum crucible and sample was heated from ambient to $700{ }^{\circ} \mathrm{C}$ at a rate of $10^{\circ} / \mathrm{min}$ in flowing air. An empty platinum crucible is used as reference. Infrared spectroscopy analysis was performed with a Nicolet 750 Magna $\mathrm{IR}^{\mathrm{TM}}$ instrument. Samples were prepared by mixing approximately $2 \mathrm{mg}$ of finely ground sample with approximately $50 \mathrm{mg}$ of the $\mathrm{KBr}$ powder and pressed in to a translucent disc. The pellet was then placed in the instrument and 100 scans were collected. ${ }^{27}$ Al MAS NMR measurement was performed using a Bruker DSX-300 spectrometer operating at 7.4 Tesla, with sender frequency of 78.21 
$\mathrm{MHz}$ and magic angle spinning at $5 \mathrm{kHz}$ in a $7 \mathrm{~mm}$ rotor. Repetition delay between scans was $1 \mathrm{~s}$ and pulse length of $0.6 \mu$ s (the $90^{\circ}$ pulse length as determined in a solution of $\mathrm{Al}^{3+}$ ions was $\left.10 \mu \mathrm{s}\right)$. A total of 1024 scans were collected and averaged. Aluminum nitrate solution was used as an external reference.

Aluminum analysis on " $40 \% \mathrm{HF}$ in Teflon" digested samples was conducted by ICP-AES using a Perkin Elmer Elan 9000 instrument. Scanning Transmission Electron Microscopy (STEM) was conducted using a Hitachi HD2000 operating at 200KV. Each sample was first evaporated from an acetone slurry onto a copper coated grid.

The nature of the acid sites was characterized by $\mathrm{NH}_{3}$-TPD and pyridine chemisorption. Approximately $50 \mathrm{mg}$ of sample was placed in a $6 \mathrm{~cm}$ long x $2 \mathrm{~cm}$ wide stainless steel tube between glass wool plugs. The sample containing tube was heated to $550^{\circ} \mathrm{C}$ at $20^{\circ} \mathrm{C}$ per min in helium, then cooled to $100{ }^{\circ} \mathrm{C}$. Several $100 \mu$ aliquots of $\mathrm{NH}_{3}$ were injected in the helium flow through a GC injector port upstream and allowed to interact with sample. Excess ammonia was allowed elute the sample was then heated in the helium flow at $10^{\circ} \mathrm{C} / \mathrm{min}$, bound ammonia allowed to desorbed through a TCD detector and temperature vs TCD detector response was recorded. For chemisorption, approximately $50 \mathrm{mg}$ of sample was placed in a $6 \mathrm{~cm}$ long $\mathrm{x} 2 \mathrm{~cm}$ wide stainless steel tube between glass wool plugs. The sample containing tube was heated to $550^{\circ} \mathrm{C}$ at $20^{\circ} \mathrm{C}$ per min in helium, then cooled to $100{ }^{0} \mathrm{C}$. Several $2 \mu$ aliquots of pyridine were injected in the 
helium flow through a GC injector port upstream and allowed to interact with sample. Excess pyridine was allowed to elute at $120^{\circ} \mathrm{C}$. The sample was then pressed into a KBR pellet and FTIR measurement (100 scans) was collected using the Nicolet 750 Magna $\mathrm{IR}^{\mathrm{TM}}$ instrument.

Catalytic studies : Cumene dealkylation was evaluated at various temperatures between $250{ }^{\circ} \mathrm{C}$ and $300{ }^{\circ} \mathrm{C}$ using a $2 \mathrm{ft}$ long $\mathrm{x} 3 \mathrm{~cm}$ wide tubular quartz, continuous up-flow fixedbed microreactor with a catalyst loading of $0.120 \mathrm{~g}$. The catalyst was held in place in the center of the tube between glass frits and quartz wool plug. The temperature was monitored with a thermocouple placed centrally in the catalyst bed. The catalyst was pretreated in-situ by heating in a $30 \mathrm{ml} / \min \mathrm{N}_{2}$ flow at $300^{\circ} \mathrm{C}$ for $1 \mathrm{hr}$. The flowing $\mathrm{N}_{2}$ (20 $\mathrm{ml} / \mathrm{min})$ was then saturated with cumene $(1.39 \mathrm{mmol} / \mathrm{min})$ by passing it through a well thermostated cumene saturator at $24^{\circ} \mathrm{C}$ and allowed to flow over the catalyst bed. The reactor effluent was passed though the sample loop of a Vaco six-port sampling valve which was interfaced to an Agilent (HP5890) GC equipped with a FID detector Gas Chromatograph. The GC conditions were as follows: oven temperature $300^{\circ} \mathrm{C}$, injection temperature $250^{\circ} \mathrm{C}$, detector temperature $250^{\circ} \mathrm{C}$, column length: $30 \mathrm{M}$, column thickness: $1.5 \mu \mathrm{m}$ and inside diameter $0.53 \mathrm{~mm}$. 


\section{RESULTS AND DISCUSSION}

\section{Porosity Characteristics of Fully Crystalline Zeolite Y Nanoparticles}

Nitrogen isotherms of zeolite Y nanoparticles synthesized according the typical methods reported is previous report is shown in Figure 1. Significant micropores adsorption activity can be observed at $\mathrm{P} / \mathrm{P}_{\mathrm{o}}<0.1$. The sample also shows mesoporous feature at $\mathrm{P} / \mathrm{P}_{\mathrm{o}} 0.8$ possibly due to void spaces between small zeolite $\mathrm{Y}$ nanoparticle aggregates. The sample shows BET surface area of $400 \mathrm{~m}^{2} / \mathrm{g}$, pore volume $0.31 \mathrm{~cm}^{3} / \mathrm{g}$ and average BJH adsorption diameter of $2.9 \mathrm{~nm}$.

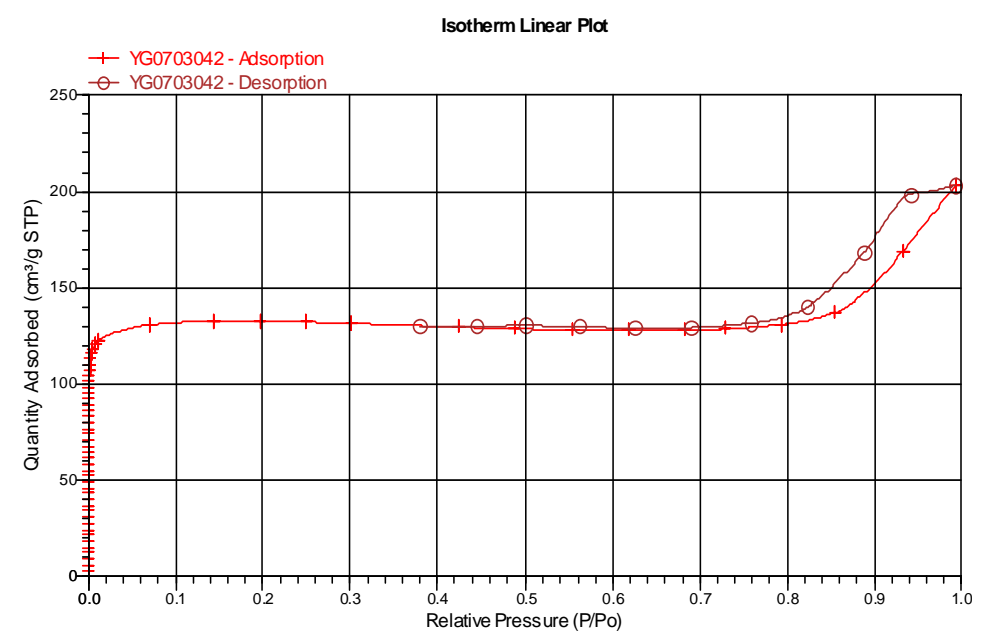

Figure 1. Adsorption-desorption isotherms of zeolite Y nanoparticles

\section{Synthesis of SBA-15/ZY Composites}

Characterizing the successful synthesis of SBA-15/ZY composites poses two primary challenges. The first is that, if one is truly successful in making such micro / 
mesoporous materials, the zeolite domains might be sufficiently small to preclude their observation by XRD. In this case, the presence of the zeolite phase can be achieved at best only by using indirect means such as catalytic testing, porosimetry, or spectroscopy. In the second case, observation of the zeolite peaks demonstrates the presence of zeolite phase but necessitate exhaustive investigation by TEM to rule out the possibility of the material in a physical mixture of bulk zeolite and mesoporous solid.

Figure 2 (a) shows XRD of a reference SBA-15 product synthesized from a low acidic media of $\mathrm{H}_{2} \mathrm{SO}_{4}$ of molar composition 4g P-123:0.041TEOS:0.24 $\mathrm{H}_{2} \mathrm{SO}_{4}: 6.67 \mathrm{H}_{2} \mathrm{O}$. The three peaks observed (one major peak at $2 \theta$ angle of $1^{\circ}$ and two smaller peaks at $1.6^{\circ}$ and $1.7^{\circ}$ angles) corresponds to the $\mathrm{d}(100), \mathrm{d}(110)$ and $\mathrm{d}(210)$ lattice reflections threedimensional hexagonally ordered nanoporous SBA-15. ${ }^{5}$ Figure 2 (b) shows XRD of product SBA-15/ZY (1.5 g zeolite Y precursor added to SBA-15). Three peaks observed (one major peak at $2 \theta$ angle of $1^{\circ}$ and two smaller peaks at $1.6^{\circ}$ and $1.7^{\circ}$ angles) corresponding to the $\mathrm{d}(100), \mathrm{d}(110)$ and $\mathrm{d}(210)$ lattice reflections three-dimensional hexagonally ordered nanoporous SBA-15. Figure 2 (c) shows XRD from product SBAZY (3 g Zeolite Y precursor). One major peak at $2 \theta$ angle of $1^{\circ}$ was observed. In Figures $2 \mathrm{a}$ and $2 \mathrm{~b}$, Zeolite $\mathrm{Y}$ peaks at $2 \theta$ angles $7^{\circ}$ and $9^{\circ}$ were not detected suggesting difficulty in observing low concentration Zeolite $\mathrm{Y}$ domains if present. 

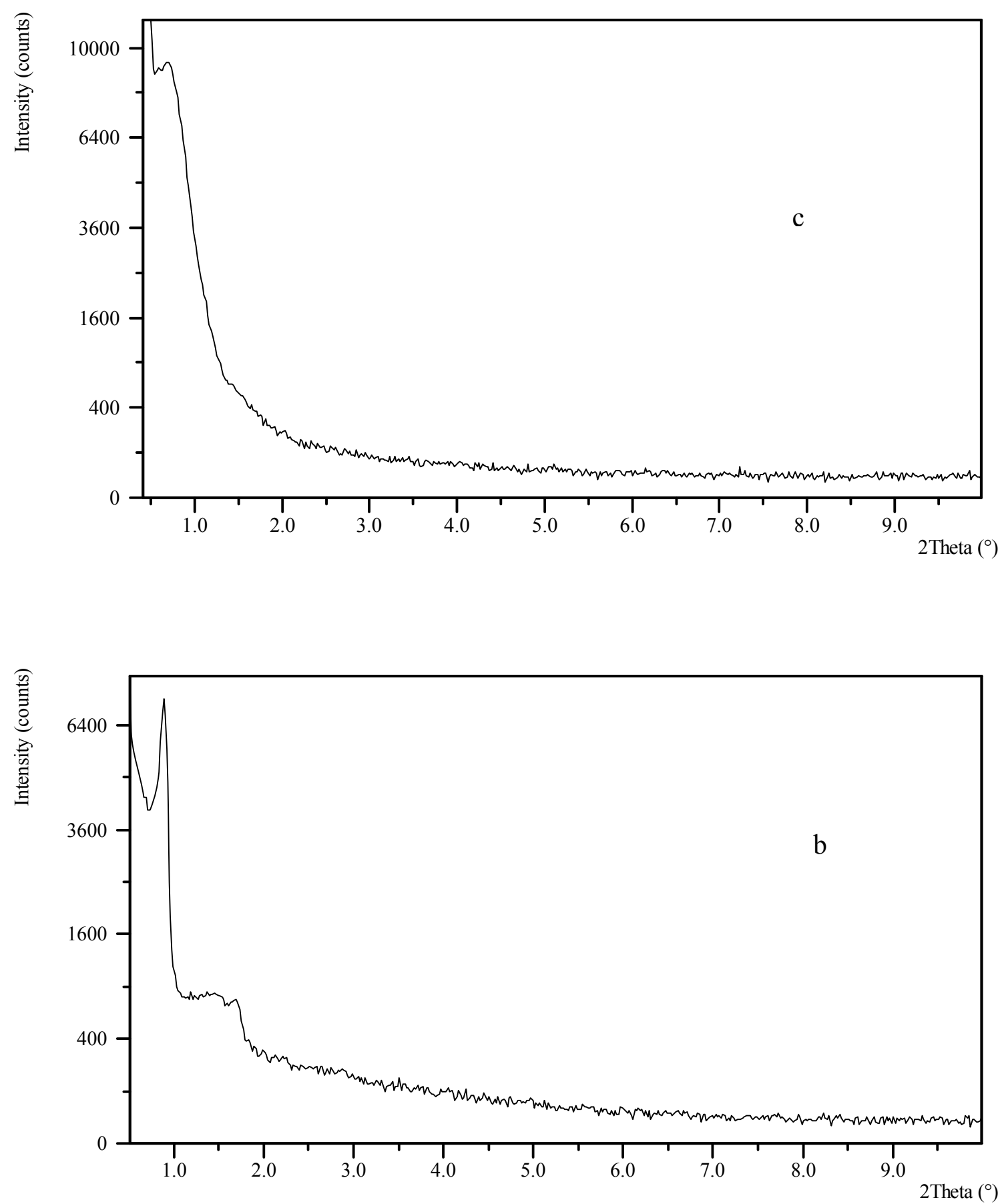


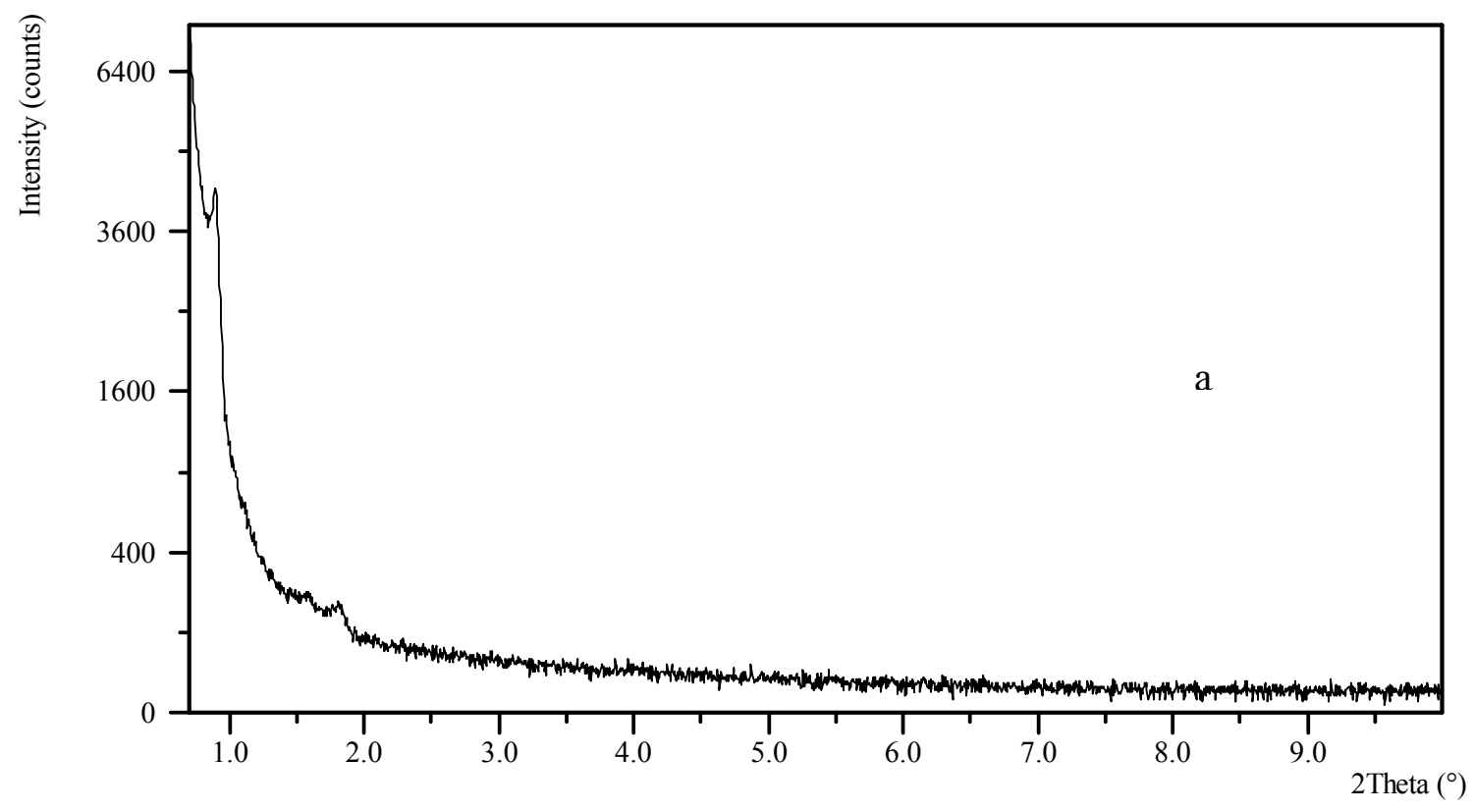

Figure 2. XRD Patterns of zeolite $Y$ samples synthesized with the addition of varying amount of aged zeolite Y precursor to SBA-15 mixture. (Zeolite Y precursor aged for 3 days at room temperature and $24 \mathrm{hr}$ at $100^{\circ} \mathrm{C} . \mathrm{a}=0 \mathrm{~g}, \mathrm{~b}=1.5 \mathrm{~g}, \mathrm{c}=3 \mathrm{~g}$ precursor).

Nitrogen adsorption-desorption isotherms of SBA-15/ZY composites with varying amount of zeolite Y precursor which was aged for $6 \mathrm{hr}$ are shown in Figure 3. Type IV isotherms were observed in all samples, therefore conforming the mesoporous nature of the sample and is typical of those observed for regular SBA-15 type materials. Hysteresis loops, typical of these materials were also observed. The samples shows different BET surface areas ranging from $350-800 \mathrm{~m}^{2} / \mathrm{g}$, pore volumes $\left(0.4-1.0 \mathrm{~cm}^{3} / \mathrm{g}\right)$ and average $\mathrm{BJH}$ adsorption diameters of 4.1 to $4.9 \mathrm{~nm}$ (Table 1). 


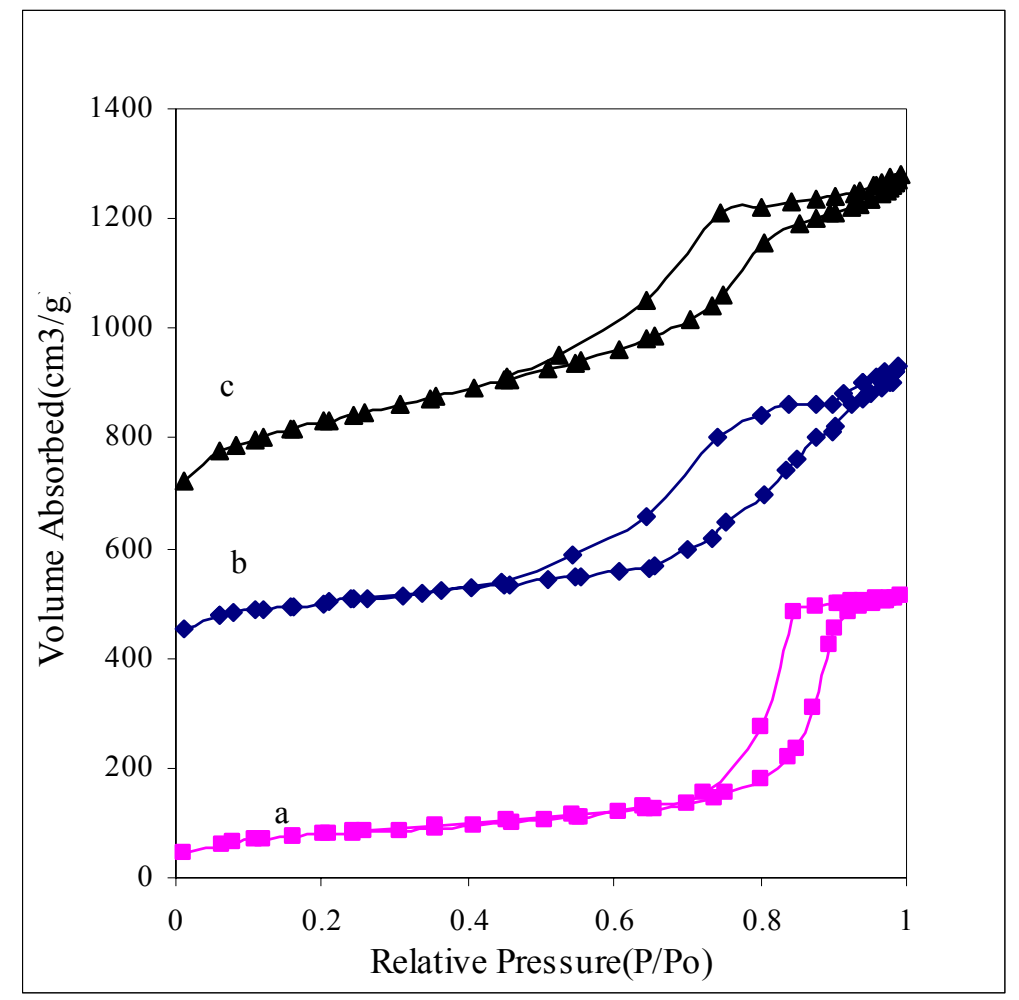

Figure 1. Adsorption-desorption isotherms of mesoporous SBA-15/ZY composites synthesized with the addition of varying amount of aged zeolite Y precursor to SBA-15 mixture. (Zeolite $Y$ precursor aged at 3 days room temperature and $6 \mathrm{hr}$ at $100^{\circ} \mathrm{C}, \mathrm{a}=0 \mathrm{~g}, \mathrm{~b}=1.5 \mathrm{~g}, \mathrm{c}=3$ g precursor.)

Nitrogen adsorption-desorption isotherms of combined SBA-15/ZYwith varying zeolite Y precursor which was aged for $10 \mathrm{hr}$ are shown in Figure 4. Type IV isotherm were observed in all samples, hence mesoporous. Hysteresis loops, typical of these materials were also observed. The samples show different BET surface areas (515 to $665 \mathrm{~m}^{2} / \mathrm{g}$ ), pore volumes $(0.8$ to $1.34 \mathrm{~nm}$ ) and average $\mathrm{BJH}$ adsorption diameter (4.1 to $5.3 \mathrm{~nm}$ ) (Table 1). 


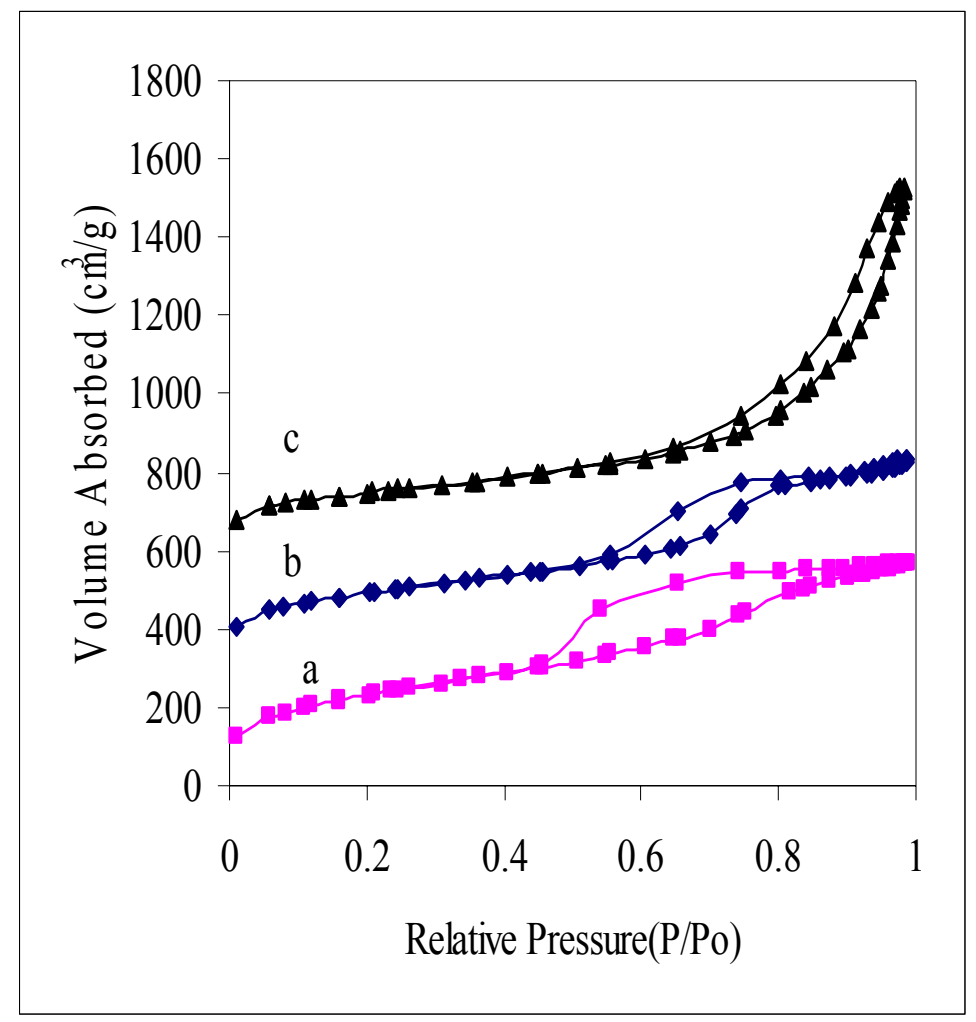

Figure 4. Adsorption-desorption isotherms of mesoporous SBA-15/ZY composite synthesized with the addition of varying amount of aged zeolite $\mathrm{Y}$ precursor to SBA-15 mixture .(Zeolite Y precursor aged at 3 days room temperature and $10 \mathrm{hr}$ at $100^{\circ} \mathrm{C}$. a $=0 \mathrm{~g}, \mathrm{~b}=1.5 \mathrm{~g}, \mathrm{c}=3 \mathrm{~g}$ precursor.)

Nitrogen adsorption-desorption isotherms of combined SBA-15/ZY composites with varying zeolite $\mathrm{Y}$ which was aged for $24 \mathrm{hr}$ are shown in Figure 5. Type IV isotherm were observed in all samples, hence mesoporous. Hysteresis loops, typical of these materials were also observed at $\mathrm{P} / \mathrm{P}_{\mathrm{o}}$ values between 0.5 and 0.9 . The samples shows 
different BET surface areas $\sim 700 \mathrm{~m}^{2} / \mathrm{g}$, pore volumes $(0.74$ to $0.96 \mathrm{~nm})$ and average BJH adsorption diameter (4.1 to $5.3 \mathrm{~nm})$ (Table 1$)$.

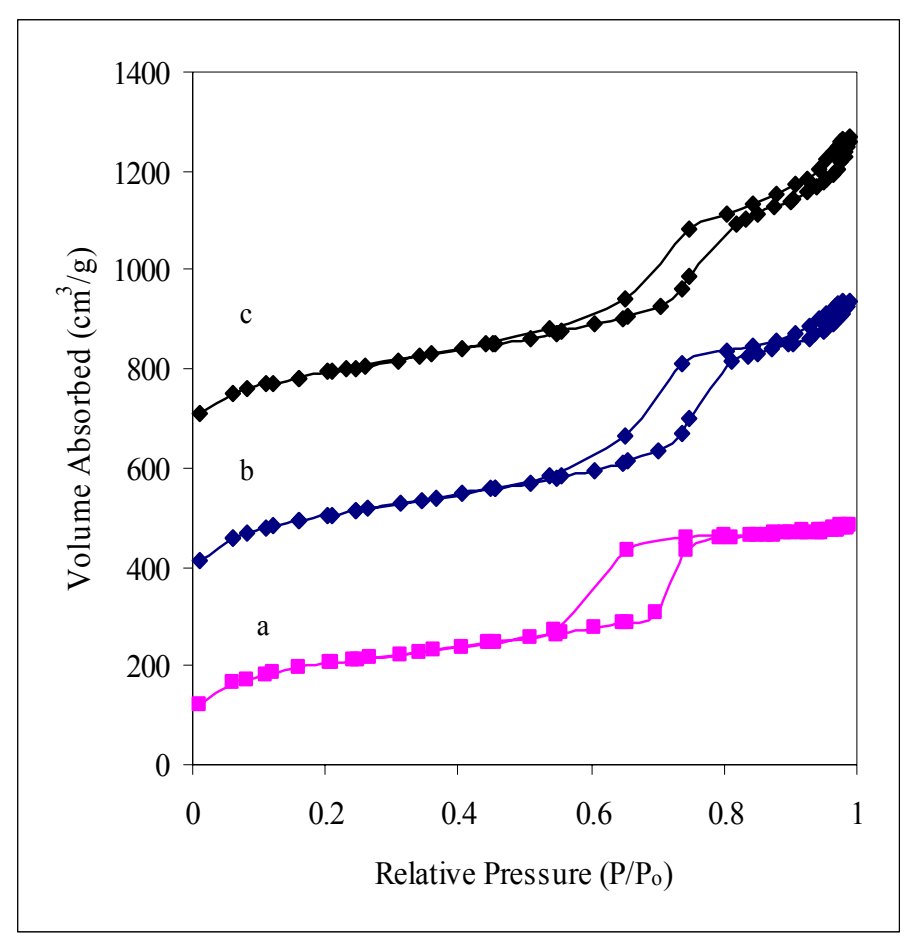

Figure 2. Adsorption-desorption isotherms of mesoporous of SBA-15/ZY composite synthesized with the addition of varying amount of aged zeolite $\mathrm{Y}$ precursor to SBA-15 mixture .(Zeolite Y precursor aged at 3 days room temperature and $24 \mathrm{hr}$ at $100^{\circ} \mathrm{C}$. a $=0 \mathrm{~g}, \mathrm{~b}=1.5 \mathrm{~g}, \mathrm{c}=3 \mathrm{~g}$ precursor.) 
Table 1. Summary of Pore Size and Surface Area of SBA-15/ZY Composites .

\begin{tabular}{|l|c|c|c|c|c|}
\hline Sample ID & $\begin{array}{c}\text { Zeolite } \mathrm{Y} \\
\text { precursor } \\
\text { heating } \\
\text { time } 100^{\circ} \mathrm{C} \\
(\text { days })\end{array}$ & $\begin{array}{c}\text { Amount of } \\
\text { Zeolite } \mathrm{Y} \\
\text { precursor mixture } \\
\text { added }(\mathrm{g}) \text { to } \\
\text { SBA-15 mixture }\end{array}$ & $\begin{array}{c}\text { Surface } \\
\text { Area } \\
\left(\mathrm{m}^{2} / \mathrm{g}\right)\end{array}$ & $\begin{array}{c}\text { Pore } \\
\text { Size } \\
(\mathrm{nm})\end{array}$ & $\begin{array}{c}\text { Pore } \\
\text { Volume } \\
\left(\mathrm{cm}^{3} / \mathrm{g}\right)\end{array}$ \\
\hline YG051805-0.5G-6HR & 0.25 & 0.5 & 350 & 4.1 & 0.37 \\
\hline YG051805-1.5G-6HR & 0.25 & 1.5 & 798 & 4.9 & 1.03 \\
\hline YG051805-0.5G -10HR & 0.42 & 0.5 & 801 & 4.2 & 0.87 \\
\hline YG051805-1.5G-10HR & 0.42 & 1.5 & 665 & 4.7 & 0.81 \\
\hline YG051805-3G - 10HR & 0.42 & 3.0 & 515 & 10.2 & 1.34 \\
\hline YG051805-5G -10HR & 0.42 & 5.0 & 552 & 8.6 & 1.24 \\
\hline YG042205-1.5G-24HR & 1 & 1.5 & 705 & 4.1 & 0.74 \\
\hline YG042205-3G-24HR & 1 & 3.0 & 706 & 5.3 & 0.96 \\
\hline
\end{tabular}

The SEM shown in Figure 30 revealed a rod-shaped morphology of SBA-15/ZY composites. TEM of the rod shaped particle shows uniform channels parallel to the rod (Figure 6). TEM of the rod shape along (d100) axis showS hexagonal pore arrangements (Figure 7). The wall average thicknesses of the SBA-15/ZY with $3 \mathrm{~g}$ precursor added was calculated $a_{0}$ - pore size $\left(a_{0}=2 \times d(100) / \sqrt{ } 3\right)$ to be $6.2 \mathrm{~nm}$, which is consistent with the value estimated from TEM (Figure 32). 


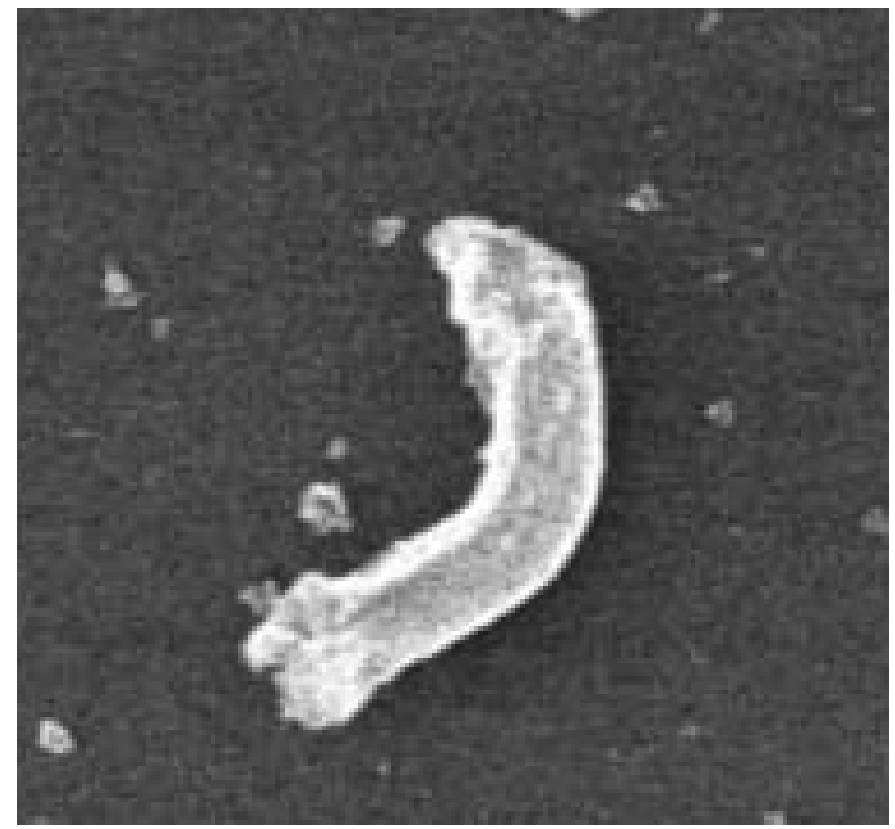

Figure 6. The SEM of SBA-15/ZYsynthesized from 3g of zeolite Y precursor aged for 24 hr.

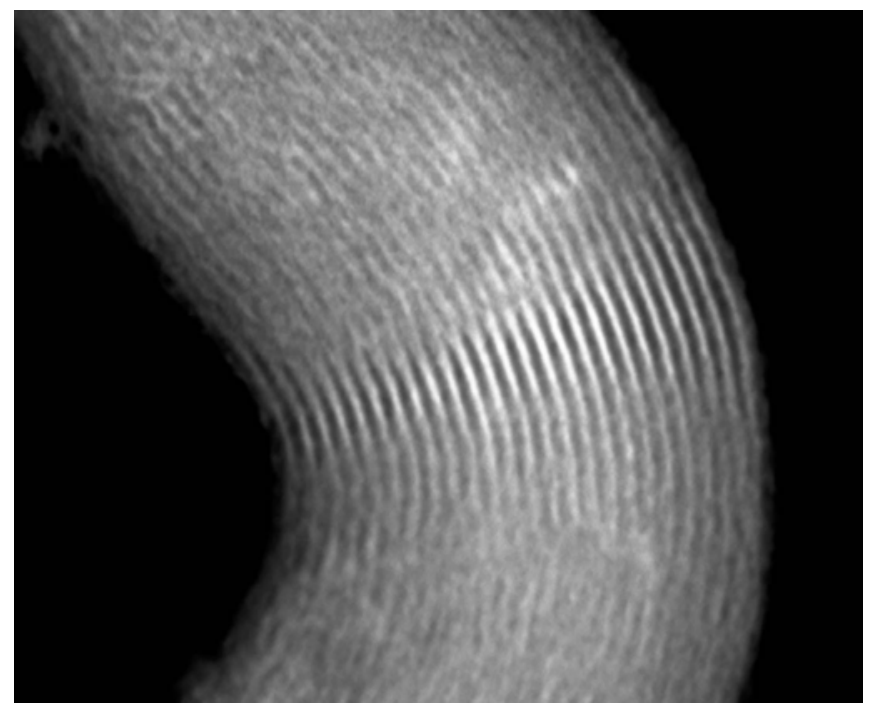

Figure 3. The TEM of SBA-15/ZYsynthesized from $3 \mathrm{~g}$ of zeolite Y precursor aged for $24 \mathrm{hr}$ image viewed d (100) axis showing pore channel. 


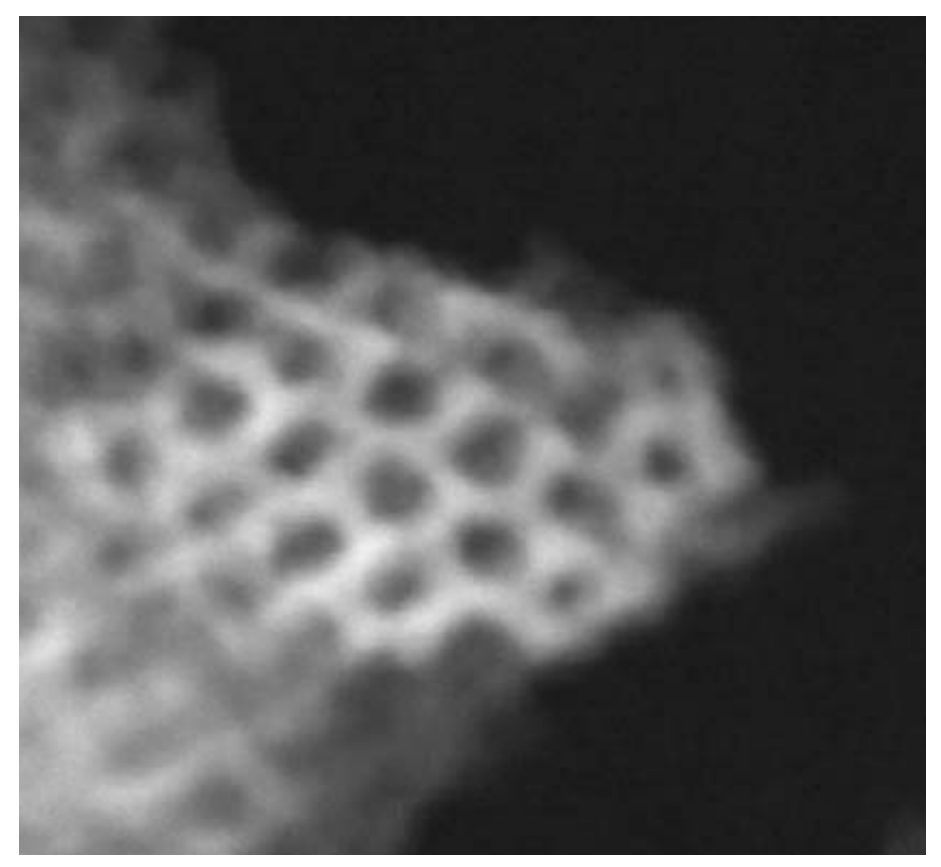

Figure 8 . The TEM of SBA-15/ZY synthesized from $3 \mathrm{~g}$ of zeolite $\mathrm{Y}$ precursor aged for $24 \mathrm{hr}$ (image viewed d (010) axis) showing hexagonal structure.

Domains of zeolite Y nanoparticles were undetected from both the SEM and TEM of bulk phase and nanoporous structure within of the SBA-15/ZY composites.

Evidence of zeolitic features within the SBA-15/ZY was explored by IR spectroscopy. The IR spectrum of a typical SBA-15/ZY sample showed bands at 570 and $470 \mathrm{~cm}^{-1}$ (Figure 9c). The band at $470 \mathrm{~cm}^{-1}$ is assigned to the structure insensitive T-O bending modes for tetrahedral $\mathrm{TO}_{4}$ units $(\mathrm{T}=\mathrm{Si}$ or $\mathrm{Al}) .^{51,29}$ The band at $570 \mathrm{~cm}^{-1}$ is attributed to the double ring external linkage associated with the zeolite $\mathrm{Y}$ and other zeolitic structures as was very prominent in a sample of zeolite $\mathrm{Y}$ nanoparticle (Figure 9b). A rational conclusion is that zeolite $\mathrm{Y}$ signature is present in the composite material. The $570 \mathrm{~cm}^{-1}$ 
peak is also observed as a very broad, but very small peak in pure SBA-15 sample, (Figure 9c).

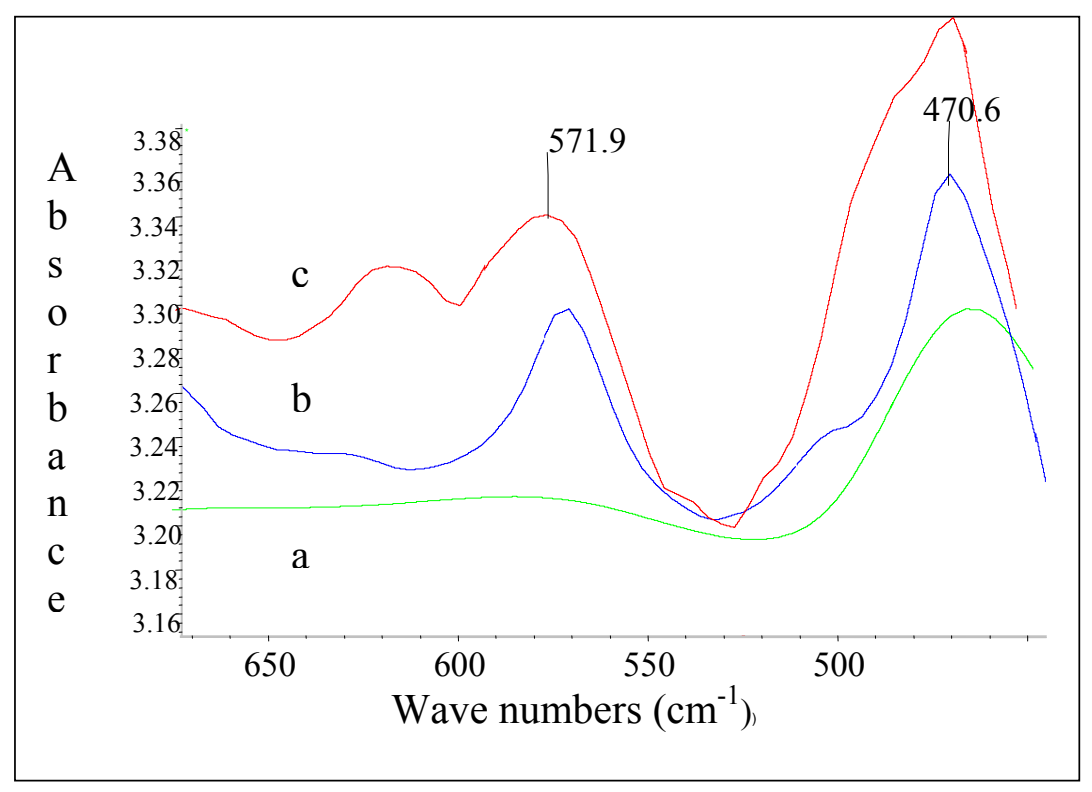

Figure 9. FTIR Spectra of (a) Pure SBA-15 synthesized in $\mathrm{H}_{2} \mathrm{SO}_{4}$ (b) pure zeolite $\mathrm{Y}$ nanocrystals (c) SBA-15/ZY. 
Table 2. Si and Al elemental analysis of SBA-15, Zeolite Y and SBA-15/ZY composites.

\begin{tabular}{|c|c|c|c|c|c|c|}
\hline Sample ID & $\begin{array}{l}\text { Catalyst } \\
\text { name }\end{array}$ & $\begin{array}{c}\mathrm{ZY} \\
\text { precursor } \\
\text { heating } \\
\text { time at } \\
100^{\circ} \mathrm{C} \\
(\mathrm{hr}) \\
\end{array}$ & $\begin{array}{l}\text { Amount of } \\
\text { ZY precursor } \\
\text { mixture added } \\
\text { to SBA }-15 \\
\text { mixture }(\mathrm{g}) \\
\end{array}$ & $\begin{array}{c}\mathrm{Si} \\
(\mathrm{mg} / \mathrm{kg})\end{array}$ & $\begin{array}{c}\mathrm{Al} \\
(\mathrm{mg} / \mathrm{kg})\end{array}$ & $\begin{array}{l}\mathrm{Si} / \mathrm{Al} \\
\text { Mole } \\
\text { ratio }\end{array}$ \\
\hline YG0422051 & SBA-15 & 24 & 0.0 & 0.16 & 0.000 & 0.0 \\
\hline YG0703045 & ZY & 24 & 0.0 & 0.09 & 0.050 & 1.9 \\
\hline YG051805 & SBA-15/ZY & 10 & 3.0 & 0.17 & 0.020 & 8.5 \\
\hline YG051805 & SBA-15/ZY & 10 & 5.0 & 0.15 & 0.020 & 10.3 \\
\hline YG042205 & SBA-15/ZY & 24 & 3.0 & 0.13 & 0.009 & 14.0 \\
\hline YG0422056 & SBA-15/ZY & 24 & 10 & 0.16 & 0.009 & 16.3 \\
\hline YG051805 & SBA-15/ZY & 10 & 0.5 & 0.23 & 0.009 & 19.5 \\
\hline YG042205 & SBA-15/ZY & 24 & 1.5 & 0.16 & 0.008 & 19.6 \\
\hline YG051805 & SBA-15/ZY & 10 & 1.5 & 0.15 & 0.006 & 27.9 \\
\hline YG051805 & SBA-15/ZY & 6 & 1.5 & 0.15 & 0.0055 & 29.0 \\
\hline YG051805 & SBA-15/ZY & 6 & 0.5 & 0.15 & 0.005 & 30.0 \\
\hline YG042205 & SBA-15/ZY & 24 & 0.5 & 0.14 & 0.004 & 36.3 \\
\hline
\end{tabular}

The coordination environment of $\mathrm{Al}$ in the product was determined by ${ }^{27} \mathrm{Al} \mathrm{SS}$ MAS/NMR. Figures 10 shows a single peak at $60 \mathrm{ppm}$ in all three samples; thus indicating that $\mathrm{Al}$ in tetrahedral $\left(\mathrm{T}_{\mathrm{d}}\right)$ coordination. This shows that the zeolitic phase survived in the mild acidic condition of SBA-15 synthesis. However the DLS analysis of a ZY precursor which was aged for $6 \mathrm{hr}$ showed no detection of particles at the instrument detection limit of $2 \mathrm{~nm}$, suggesting the absence of crystalline ZY phases. The presence of $\mathrm{Al}$ in $\mathrm{T}_{\mathrm{d}}$ coordination in $\mathrm{SBA} / \mathrm{ZY}$ composite must therefore be derived from 
pre-crystalline building blocks of ZY in the precursor. The absence of NMR peak at 0 ppm indicates the absence of octahedral $\left(\mathrm{O}_{\mathrm{h}}\right)$ coordinated $\mathrm{Al}$, and hence the absence of undesirable extra-frame work $\mathrm{Al}$ species. This method of introduction of $\mathrm{Al}$ in a purely $T_{d}$ coordination is therefore more effective in comparison to direct and post synthesis alumination methods. ${ }^{30,31} \mathrm{SBA} / \mathrm{ZY}$ samples from ZY precursor aged for 6 and $10 \mathrm{hr}$ showed stronger $T_{d}$ peaks that from seed aged for $24 \mathrm{hr}$. The possibility is that at $24 \mathrm{hr}$ aging, the precursor contains a mixture of building blocks in addition to and well-formed zeolite $\mathrm{Y}$ nanoparticles of $\sim 50 \mathrm{~nm}$ particle size (Previous report). The non-crystalline precursor could be incorporated within the structure of SBA-15, but well formed nanocrystals were probably lost during the washing and filtration process.

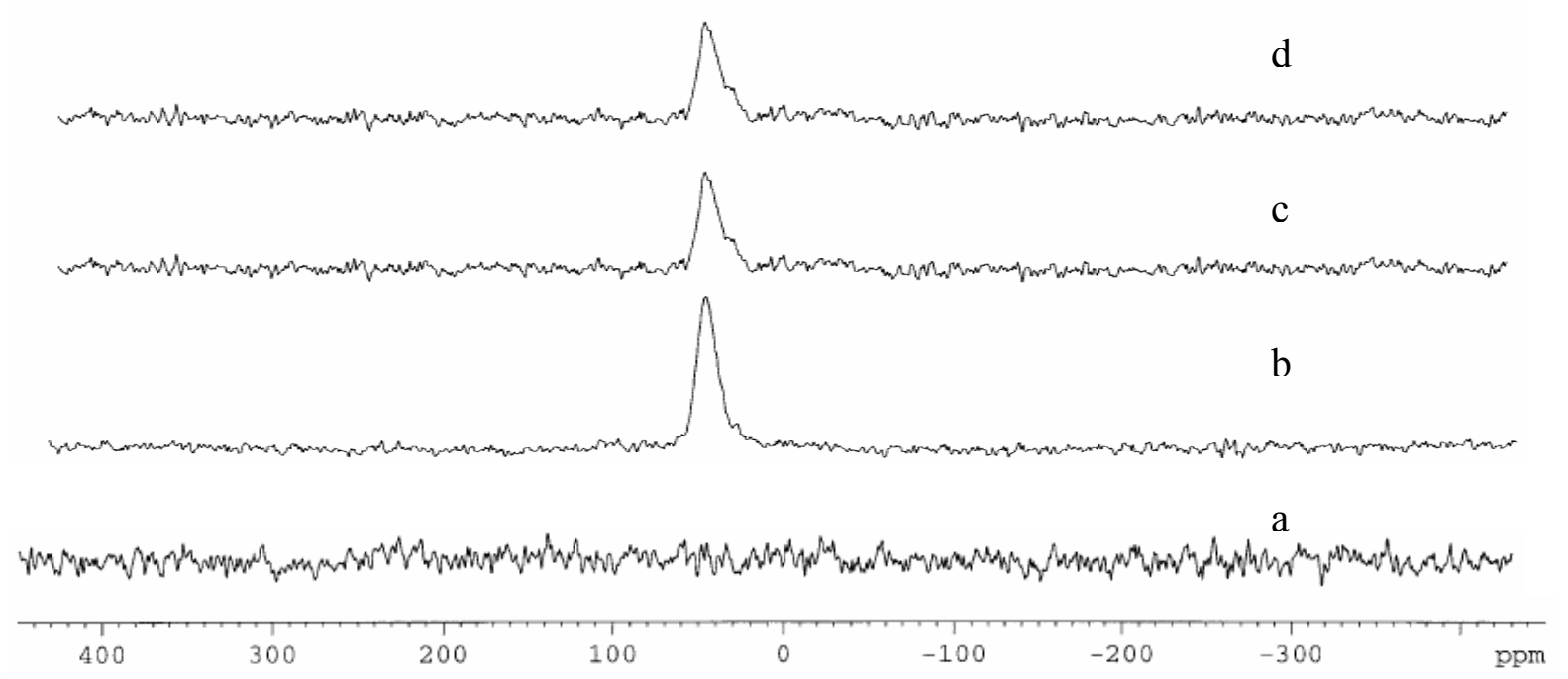

Figure 10. ${ }^{27} \mathrm{Al}$ SS NMR spectra of a) pure SBA-15, and SBA-15/ZY composite with $3 \mathrm{~g}$ of ZY precursor after aging for (b) $6 \mathrm{hr}$ (c) $10 \mathrm{hr}$ and (d) $24 \mathrm{hr}$. 
In Figure 11 it is shown that in SBA-15/ZY composites from precursor aged for $10 \mathrm{hr}$, as the amount precursor added was increased the $T_{d} A l$ phase become more pronounced and octahedral Al species was absent up to $\mathrm{Si} / \mathrm{Al}$ of 8.5 studied.

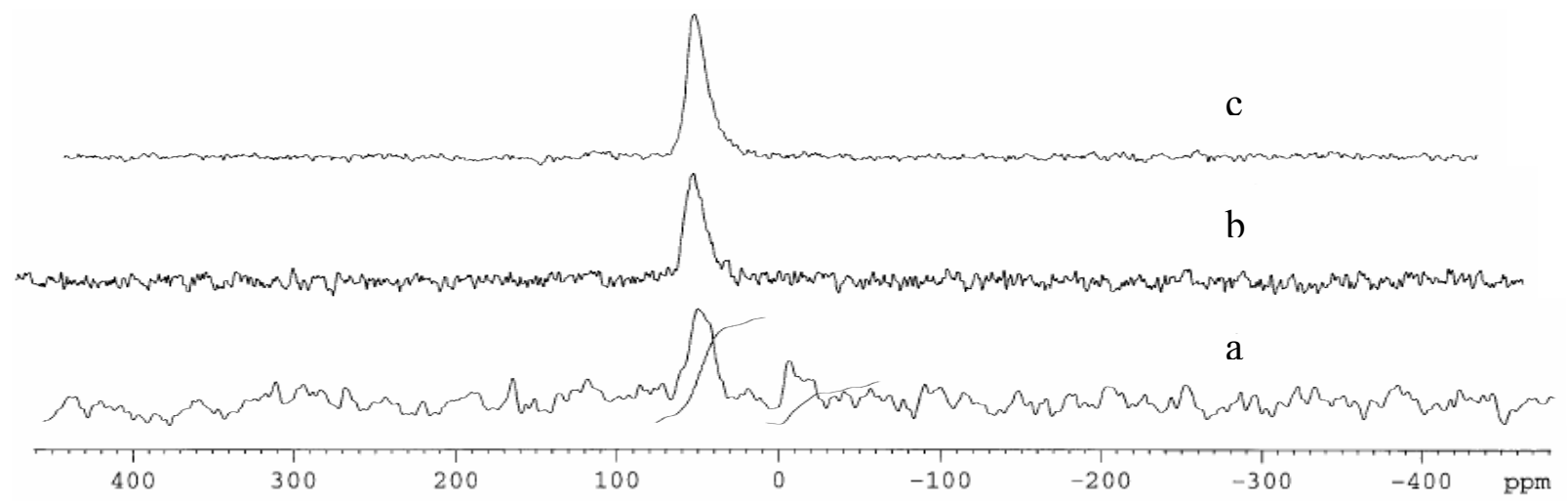

Figure 11. NMR spectra of SBA-15/ZY composite from different amount of 10 varying amount of $10 \mathrm{hr}$ aged $\mathrm{ZY}$ precursor (a. $0.5 \mathrm{~g}$ b. $1.5 \mathrm{~g} \mathrm{c.} 3 \mathrm{~g}$ )

A similar situation was observed for precursor aged for $24 \mathrm{hr}$ (Figure 12). Though this case the ${ }^{27} \mathrm{Al}$ signal was weaker compared with that from the $6 \mathrm{hr}$ precursor for the reasons suggested earlier. This is consistent with chemical analysis which confirmed that as the amount of ZY precursor was incorporated the Al content of the SBA-15/ZY composite also increased proportionally (Figure 13). 


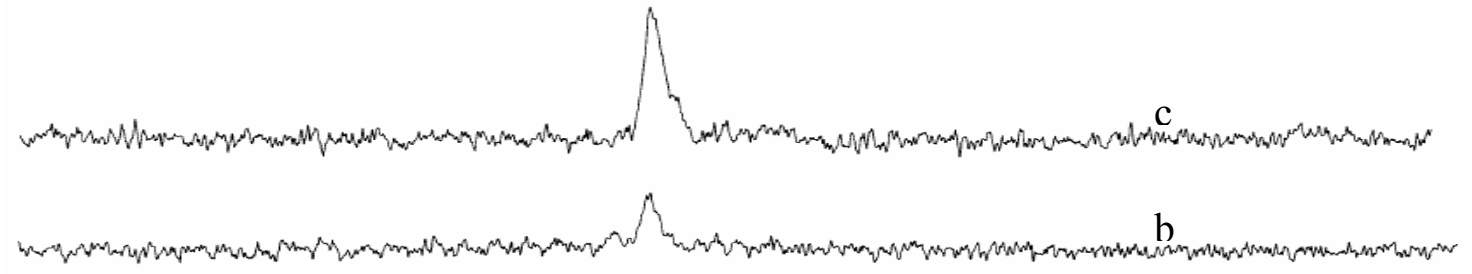

a

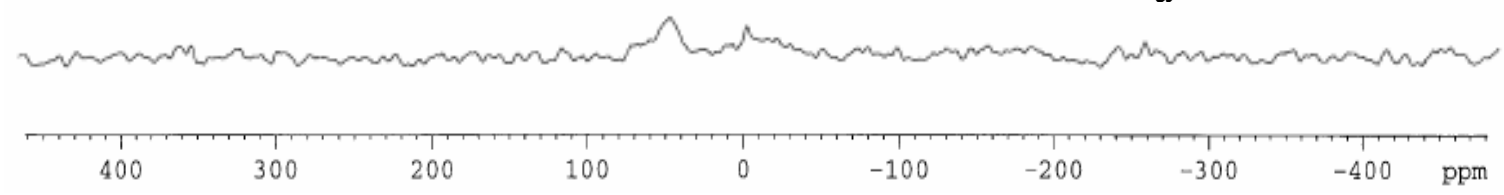

Figure 12. NMR spectra of SBA-15/ZY composite from different amount of 10 varying amount of $24 \mathrm{hr}$ aged $\mathrm{ZY}$ precursor (a. $0.5 \mathrm{~g}$ b. $1.5 \mathrm{~g} \mathrm{c} .3 \mathrm{~g}$ )

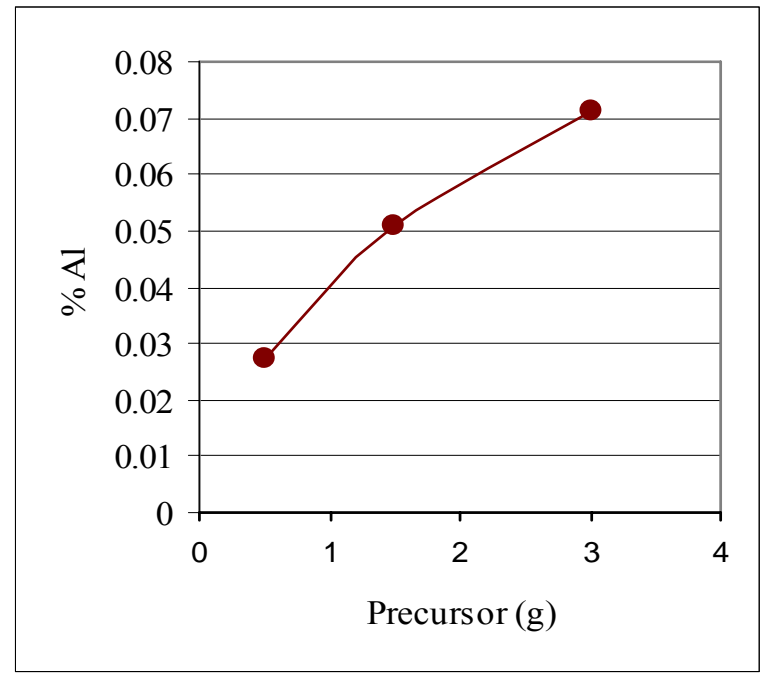

Figure 13. Graph showing the amount of Al in SBA-15/ZY product vs. amount of $6 \mathrm{hr}$ aged ZY precursor added. 


\section{Acidity and Catalytic Activity}

The nature of the acid sites of a representative SBA-15/ZY composite was evaluated by measuring the IR spectrum of pyridine adsorbed on the surface. Figure 14 shows the IR spectrum of the catalyst with SBA-15/ZY composite (Si/Al 19.6). The spectrum shows peaks due to pyridinium ions on Bronsted acidic sites $\left(1546 \mathrm{~cm}^{-1}\right)$ and strongly Lewisbound pyridine $\left(1456 \mathrm{~cm}^{-1}\right)$. The peak at $1494 \mathrm{~cm}^{-1}$ is assigned to pyridine associated with both Bronsted and Lewis acidic sites. ${ }^{32}$ As expected, these peaks were absent in the pure SBA-15 in which no aluminum was added to the synthesis mixture (not shown).

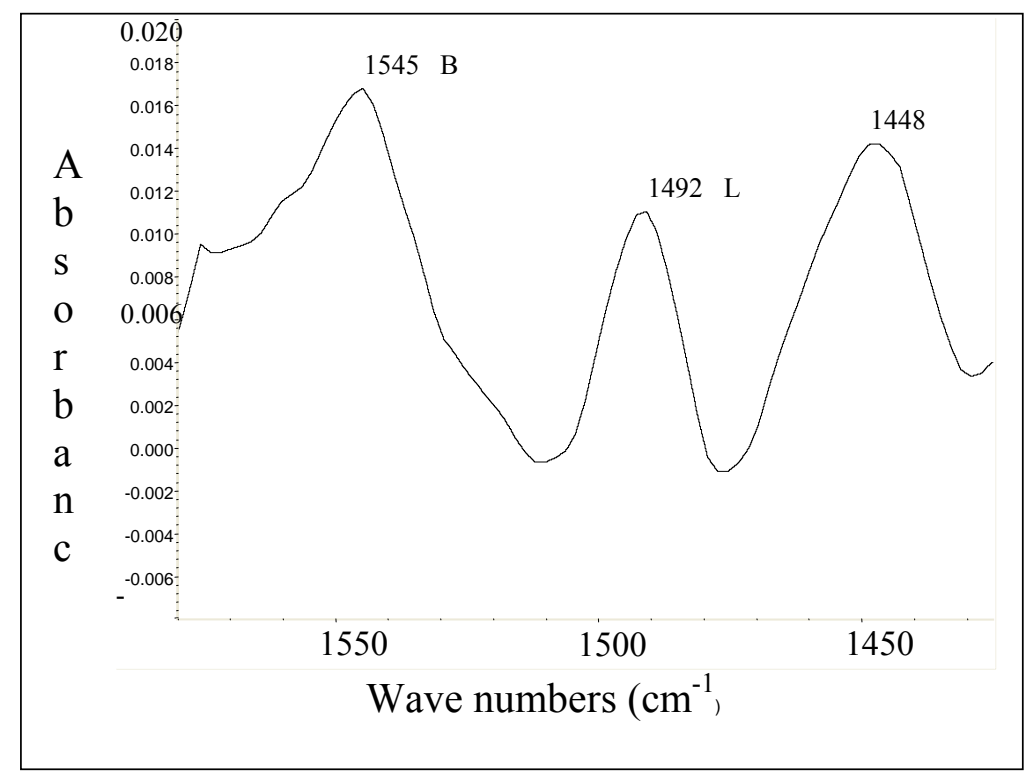

Figure 14. FTIR spectra of pyridine absorption on SBA/ZY composite. 
The relative strength of acid sites was compared using $\mathrm{NH}_{3}$-TPD measurements on the a typical synthetic SBA-15/ZY composite and physical mixture of commercial ZY with pure SBA-15 (Figures $15 \mathrm{~b}$ and c) respectively). Both the synthetic and blended composite materials show ammonia desorption peaking at about $350^{\circ} \mathrm{C}$, thus showing that the strength of acid sites in the composites were similar to those in commercial ZY. The $\mathrm{NH}_{3}$-TPD of the pure SBA-15 showed far less response which indicates, little or no acidic sites present (Figure 15 a). The results were consistent with the NMR results (vide infra) and catalytic activity (vide supra).

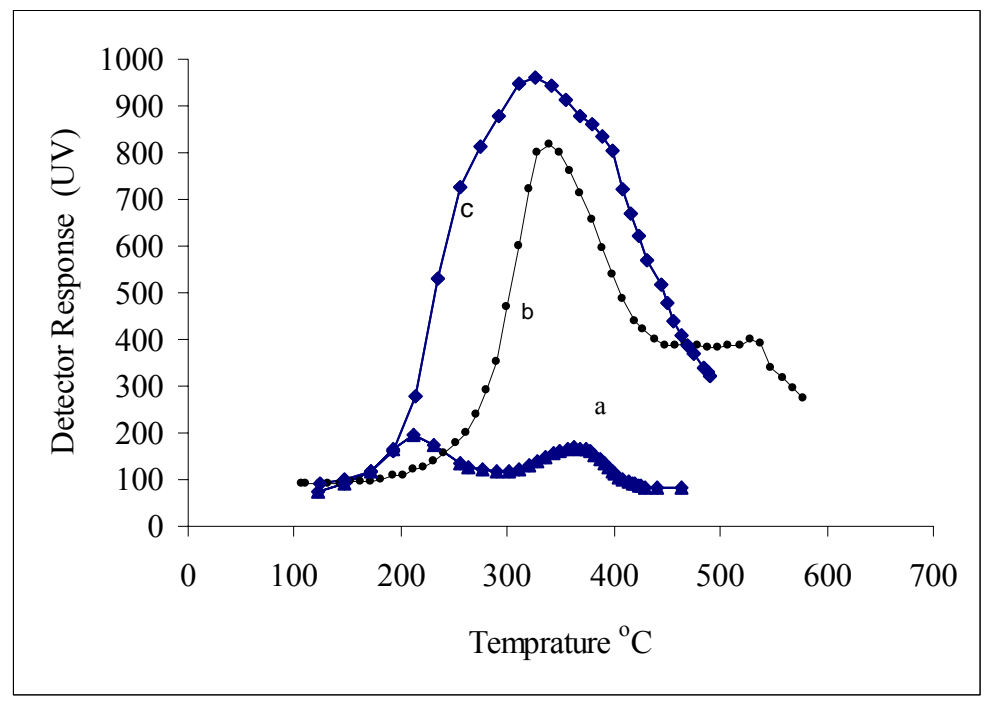

Figure 15. $\mathrm{NH}_{3}$-TPD on (a) Pure SBA-15 synthesized in of $\mathrm{H}_{2} \mathrm{SO}_{4}$ (b) SBA-15/ZY composite synthesized by the addition of $3 \mathrm{~g}$ of zeolite precursor (c) physically mixed commercial ZY with SBA-15 synthesized by the addition of $\mathrm{H}_{2} \mathrm{SO}_{4}$. 


\section{Catalysis}

The catalytic activities of SBA-15/ZY materials were evaluated by acid catslyzed dealkalytion of cumene. The main products were benzene and propene as confirmed by GC/MS (Figure 16). ${ }^{56}$ The proposed dominant pathways involved dealkylation and dehydrogenation of the side chain. This involves the cleavage of the propyl group from the benzene ring with latter remaining unaltered as illustrated in Figure $17 .^{33}$

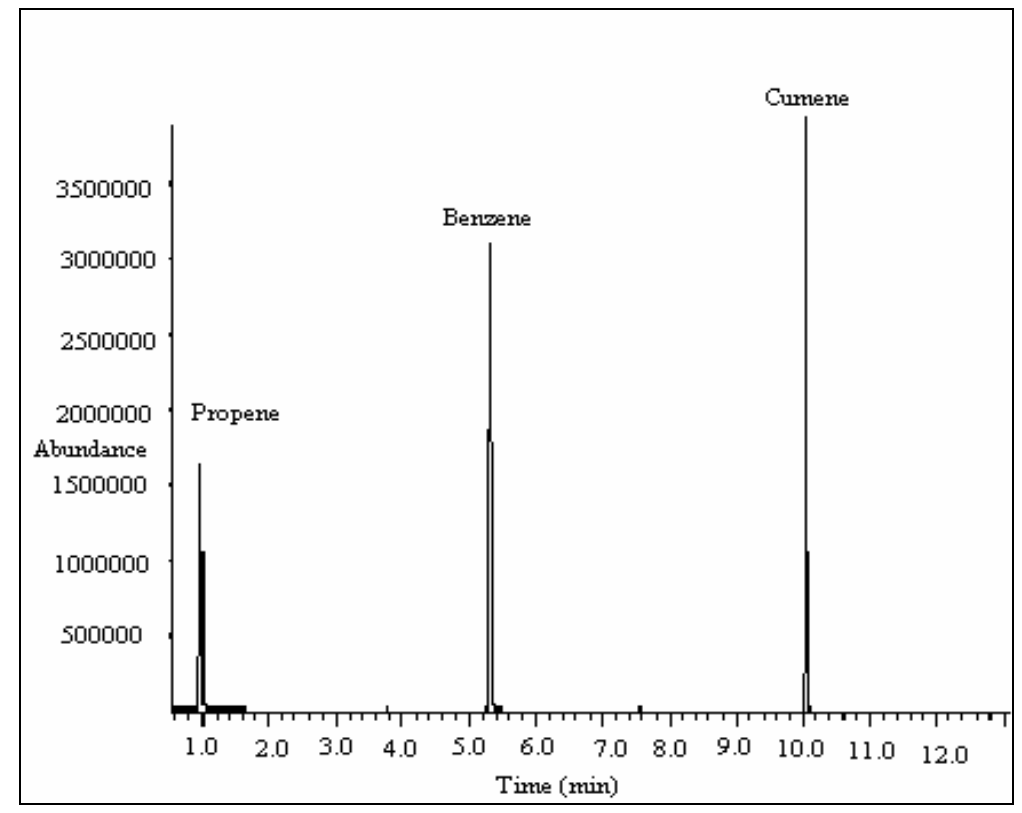

Figure 4. GC/MS chromatogram showing cumene dealkalytion products. 


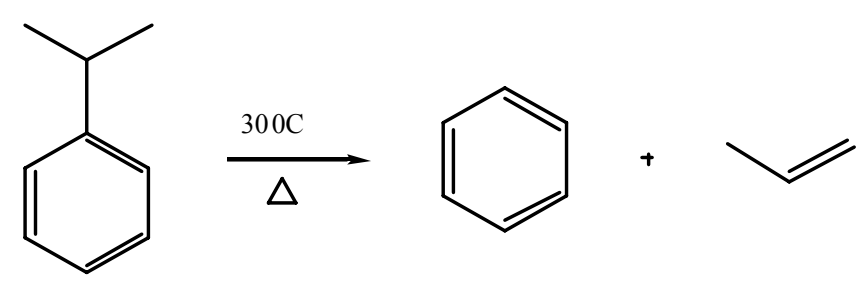

Figure17. Schematic illustration of the catalytic dealkylation of cumene.

Figure 18 shows the percent conversion of cumene with various SBA-15/ZY composites. Increase in percentage cumene conversion with increase in percentage $\mathrm{Al}$ in the composite were observed, and initial percentage conversion ranged from $\sim 10-15 \%$ for $(\% \mathrm{Al})$,to $30 \%$ for $(\% \mathrm{Al})$, to $\sim 60 \%$ for $(\% \mathrm{Al})$. $\mathrm{Up}$ to $\% \mathrm{Al}$ the catalyst activity remained fairly constant for $\mathrm{x}$ hr. For sample with $\mathrm{x} \% \mathrm{Al}$, rapid decline in catalytic activity was observed. This is possibly due to the larger percentage of acidic sites present which resulted in heavy catalytic activity, hence rapid catalyst deactivation. 


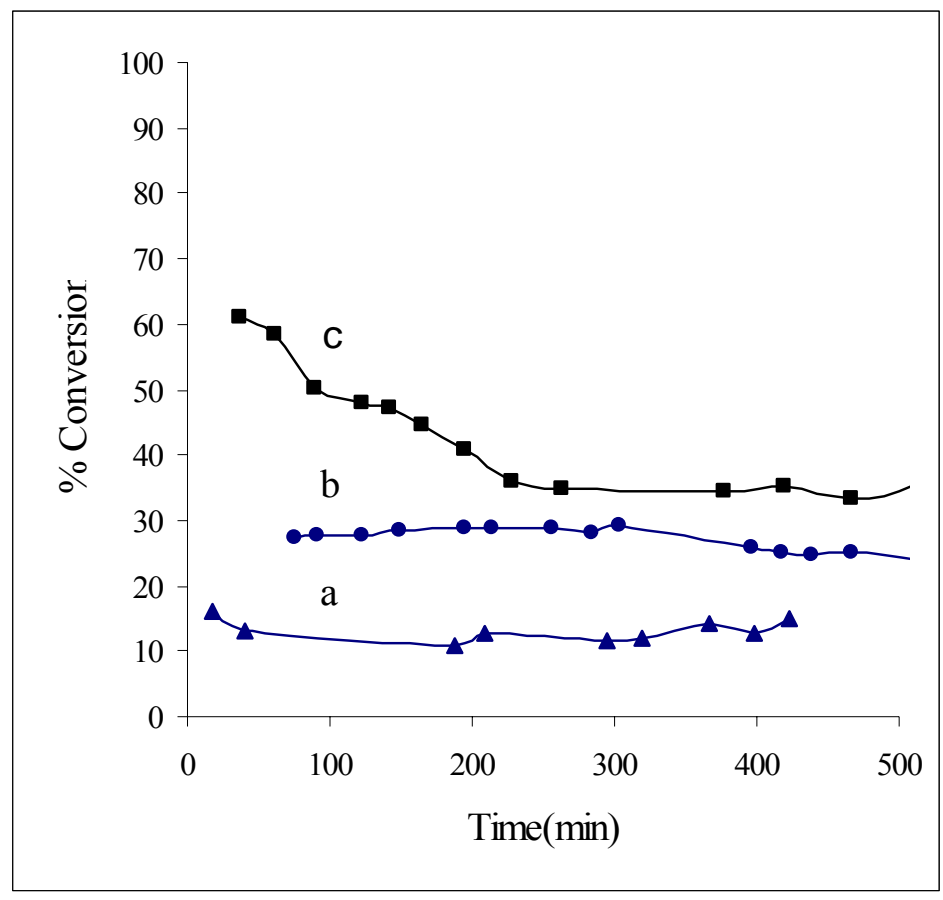

Figure18. Cumene dealkaylation vs. time for various SBA-15/ZY composites made from different weight of $6 \mathrm{hr}$ aged ZY precursor (a) $0.5 \mathrm{~g}$, (b) $1.5 \mathrm{~g}$ and (c) $3 \mathrm{~g}$.

Similar results were observed for SBA-15/ZY composites precursor aged for $10 \mathrm{hr}$ and $24 \mathrm{hr}$ (Figure 19). 


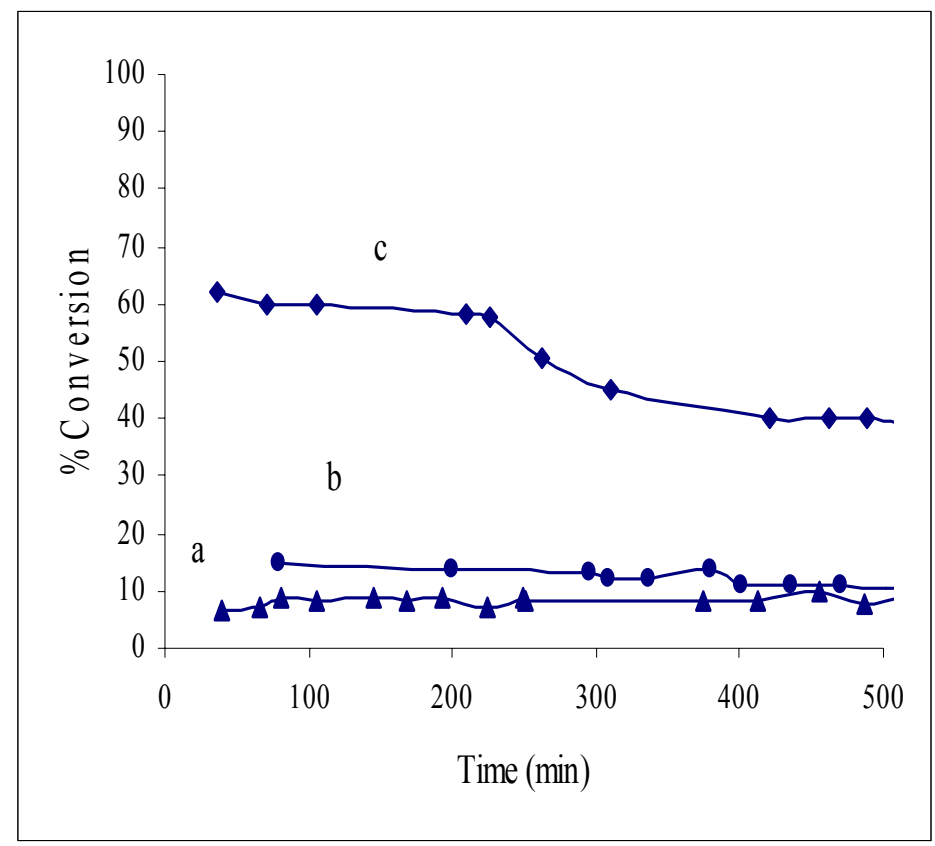

Figure 20. Cumene dealkaylation vs time for various SBA-15/ZY composites made from different weight of $10 \mathrm{hr}$ aged $\mathrm{ZY}$ precursor (a $0.5 \mathrm{~g}$, (b $1.5 \mathrm{~g}$ and (c $3 \mathrm{~g}(\% \mathrm{Al})$.

Figure 21 shows the percent conversion of cumene with SBA-15/ZY composite material made from varying amounts of $24 \mathrm{hr}$ aged $\mathrm{ZY}$ precursor. It was observed that higher conversion for catalysts synthesized resulted from higher amounts of ZY precursor mixture added to the SBA-15 at $24 \mathrm{hr}$. This indicates that catalysts with higher amount of precursor added have more acid sites cumene. This was consistent with the chemical analysis and the NMR results. 


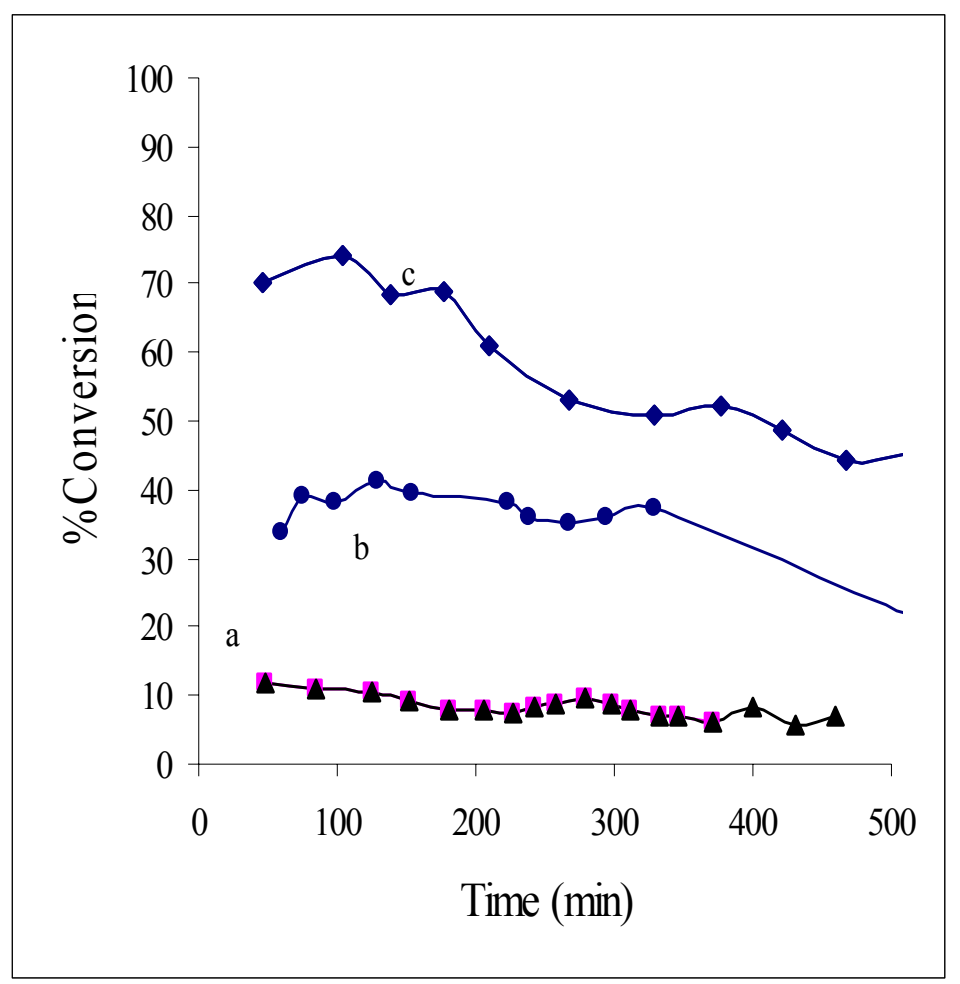

Figure 21. Catalytic activity of composite materials of SBA-15/ZY synthesized with the addition of (a) $0.5 \mathrm{~g}$, (b) $1.5 \mathrm{~g}$ and (c) $3 \mathrm{~g}$ of ZY precursor mixture heated for $24 \mathrm{hr}$ at $100^{\circ} \mathrm{C}$.

Figure $22(a, b, c)$ compares the percent conversion of cumene with SBA-15/ZY composites vs a physical blend of pure SBA-15 and commercial ZY. The rates of catalyst deactivation was apparent comparable for both. 


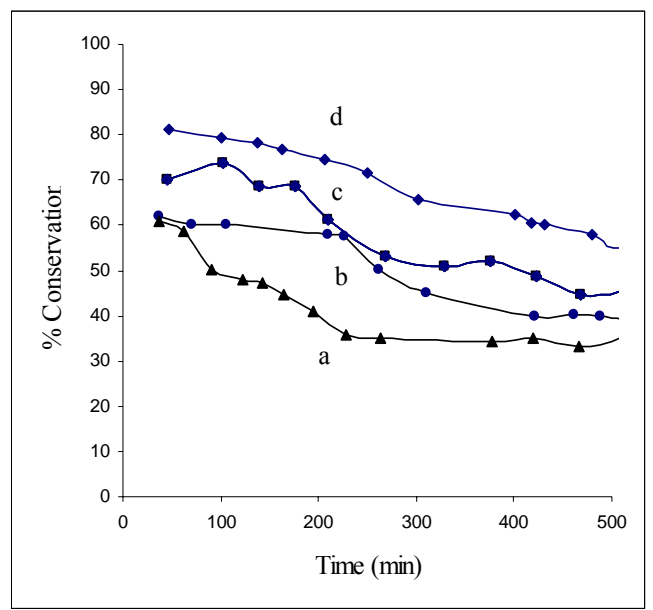

Figure 22. Catalytic activity of composite materials of SBA-15/ZY synthesized with the addition of $3 \mathrm{~g}$ zeolite $\mathrm{Y}$ precursor aged for (a) 6, (b) 10, (c) $24 \mathrm{hrs}$ vs (d) a physical mixture of commercial ZY and pure SBA-15 synthesized with $\mathrm{H}_{2} \mathrm{SO}_{4} 100{ }^{\circ} \mathrm{C}$.

To determine the intrinsic strength of the composites, the rate of cumene conversion on SBA/ZY was also compared with a sample of pure nanocrystalline Zeolite $\mathrm{Y}$ at different temperatures (Figure 23). The results suggest that the composite is more active that the pure ZY nanoparticles.

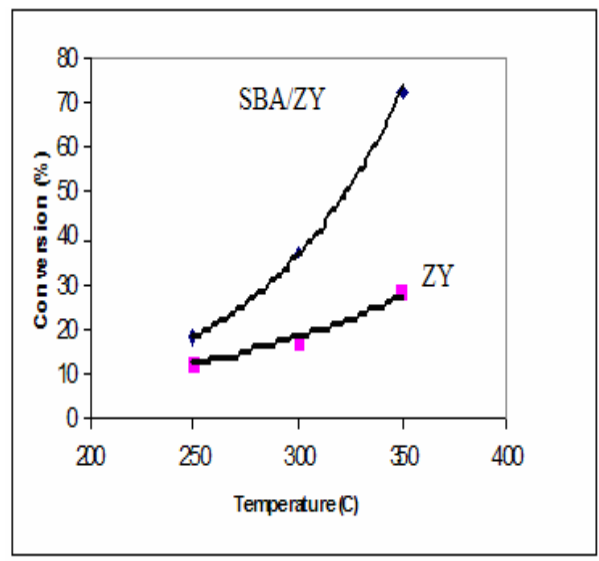


Figure 23. Cumene conversion vs tempareture on SBA/ZY and pure Zeolite Y nanoparicles $(79 \mathrm{~nm})$.

\section{CONCLUSIONS}

Composite materials of SBA-15/zeolite Y were synthesized from a precursor of zeolite Y seeds and a mesoporous silicate SBA-15 via a hydrothermal process in the presence of a slightly acidic media of $\mathrm{pH} 4-6$ with $2 \mathrm{M} \mathrm{H}_{2} \mathrm{SO}_{4}$. The SBA-15/ZY composites showed type IV adsorption isotherms, narrow BJH average pore size distribution of 4.9 $\mathrm{nm}$, surface areas up to $800 \mathrm{~m}^{2} / \mathrm{g}$ and pore volumes $1.03 \mathrm{~cm}^{3}$, all comparable to pure SBA-15 synthesized under similar conditions. Chemical analysis revealed Si/Al ratio of 14 in the most aluminated sample, and SS MAS NMR confirmed aluminum was in tetrahedral coordination in the SBA-15/ZY composites, hence this method of introduction of $\mathrm{Al}$ in a pure $\mathrm{T}_{\mathrm{d}}$ coordination is effective in compare to other direct and post synthesis alumination reported ------. Bronsted acid sites were evident from a pyridinium peak at $1544 \mathrm{~cm}^{-1}$ in the FTIR spectrum after pyridine adsorption, and from $\mathrm{NH}_{3}$-TPD experiments. SBA-15/ZY composites showed significant catalytic activities for the dealkylation of isopropylbenzene to benzene and propene, similar to those of commercial zeolite Y. It was observed that higher conversion for catalysts synthesized with high amount of ZY precursor mixture added to the SBA-15. Over all the composites indicate successful in incorporating Al in to activity mesoporous SBA-15 and showed a good catalyts. 
Further studies needed to better understand the nature of the precursor, and to characterize and locate the acid sites in the composite material. This will help to identify effective methods of incorporation of acid sites (Al) to mesoporous SBA-15 to obtain best catalyst.

\section{FUTURE WORK}

Further studies will be focused on gaining a better understand the nature of the precursor, and to characterize and to locate the acid sites in the composite material. The composite will also be evaluated for heavy oil conversion to naphtha and middle distillates.

\section{TECHNOLOGY/INFORMATION TRANSFER}

\section{$\underline{\text { Students: }}$}

Two following two students have been working on the project since inception:

Tesfarmariam

Yohannes Ghirmazion

Fengling Ding

Ifedapo Adeniyi

Taurean Hodges

Selassi Blavo
$\mathrm{Ph}$. D. students (Chemistry)

M.S. graduate student (Chemistry)

M.S. graduate student (Chemistry)

Sophomore undergraduate (Chemistry \& Engineering)

M.S. graduate student (Chemistry)

Senior (Chemistry and Chemical Engineering)

\section{Presentations:}

1) Synthesis and Catalytic Properties of Hierarchical Mesoporous Aluminosilicate Assembled from Zeolite Y Precursors, Yohannes Ghirmazion, presented at the Chemistry Department, Calrk Atlanta University, Atlanta GA, November 22, 2005.

2) Synthesis of Mesoporous Solids Containing Zeolitic Phase from Hydrothermal Treatment of Colloidal Zeolite Y Precursors, Yohannes Ghirmazion and Conrad W. Ingram to be presented at Pacifichem 2005; December 15-20, 2005, Honolulu, Hawaii, USA 
3) Synthesis and Catalytic Properties of Hierarchical Mesoporous Aluminosilicate Assembled from Zeolite Y Precursors, Conrad W. Ingram, Yohannes Ghirmazion, and Ifedapo Adeniyi, to be presented at the Singapore International Chemical Conference 4, December 8-10, 2005 Shangri-La Hotel, Singapore.

4) Enhancing the Catalytic Properties of Ordered Nanoporous Silicate Using Hydrothermally Treatment Zeolitic Precursors, Conrad W. Ingram, Yohannes Ghirmazion, and Ifedapo Adeniyi; Nanomaterials and Composites: Synthesis, Properties and Applications II57th Southeast / 61stSouthwest, Joint Regional Meeting of the American Chemical Society, November 1 - 4, 2005, Memphis, Tennesse

5) Preparation of Nanosized Micro/Mesoporous Composites via Sequential Synthesis of zeolite Y/SBA-15 Phases; Yohannes Ghirmazion and Conrad W. Ingram, to be presented at the ACS National Meeting, Washington DC, August, 2005.

6) On the Synthesis of Zeolite Y Nanocrystals in the Presence of Tetramethylammonium Bromide, Yohannes Ghirmazion* and Conrad W. Ingram, presentated at the 227 ACS National Meeting, Anaheim, California, March 28 - April 1, 2004 .

7) Non Ionic Surfactant Mediated Templated Synthesis of Phenylene-Bridged Organosilicate, Yohannes Ghirmazion*, Conrad Ingram, presented at the 55th Southeast Regional Meeting (SERMACS), Atlanta, GA, November 16-19, 2003.

8) A Comparison of Synthesis Strategies for Aryl Functionalized Ordered Nanoporous Organosilicates using Nononionic and Cationic Surfactants, Yohannes Ghirmazion*, Conrad Ingram presented at the 55th Southeast Regional Meeting (SERMACS), Atlanta, GA, November 16-19, 2003.

9) Phenylene-Bridged Mesoporous Organosilicate from Nonionic Surfactant Templated Synthesis, Conrad Ingram* and Yohannes Ghirmazion, presentated at the 4th International Mesostructured Material Symposium, May 1-4, 2004, Cape Tow, South Africa.

10) Synthesis of Aromatic Bridged Ordered Mesoporous Organosilicate with Cetyltrimethylammonium Cation as Templating Agent was presented at the 4th International Mesostructured Material Symposium, May 1 -4, 2004, Cape Tow, South Africa.

\section{REFERENCES}

1 Stocker . M. et al. Microporous and Mesoporous Materials, 27,1999,17

2 Shantz D.F, Kaskel .S. Carr. C.S.Chem. Mater.2004, 16, 139-3146.

3 Sun Y.Han.Y. et al, J.Phys.Chem.B. 2003, 07, 1853-1857.

4 Stocker .M. Arne .K. Schmidt .R. Microporous and Mesoporous Materials, 27, 1999,181

5 Zhou, D; Feng J.; Hou, Q.; Melosh, N., Frederickson, G.; Chmelka, B.; Stuky, G.; Scinece.1998, 279,549. 
6 Dimitriu, E.; On, D. T.; Kalaguine, S. J. Catal. 1997, 170, 150.

7 Mokaya, R. Angew. Chem., Int. Ed. 1999, 38, 2930.

8 D. Zhao, J. Feng, Q. Huo, N. Melosh, G. H. Frederickson,B. F. Chmelka and G. D. Stucky.Science.1998,

9 Juan A. Melero, Galen D. Stucky, Rafael van Grieken and Gabriel Morales.J. Mater. Chem., 2002, 12 ,6, $1664-1670$

10 Zhang, W., T.R. Pauly, and T.J. Pinnavaia. Chem. Mater. 1997. 9: p. 2491-2498

11 Zhang, W., et al. J. Am.Chem. Soc, 1996, 118.9164-9171

12 Yu Liu and Thomas J. Pinnavaia Journal of Materials Chemistry, 2004, 14(7), 1099 1103

13 N. Petkov, M. Hollzl, T. H. Metzger, S. Mintova,,and T. Bein J. Phys. Chem. B 2005, $109,4485-4491$

14 Liu, Y.; Zhang, W.; Pinnavaia, T. J. Angew. Chem., Int. Ed. 2001, 40, 1255.

15 Zhang, Z. T.; Han, Y.; Xiao, F. S.; Qiu, S. L.; Zhu, L.; Wang, R.W.; Yu, Y.; Zhang, Z.; Zou, B. S.; Wang, Y. Q.; Sun, H. P.; Zhao, D. Y.;Wei, Y. J. Am. Chem. Soc. 2001.123. 5014.

16 Jiahui Huang,a Gong Li,b Shujie Wu,a Hongsu Wang,a Lihong Xing,a Ke Song,a Tonghao Wua and Qiubin Kan. J. Mater. Chem.2005, 15, 1055-1060.

17 Van der Voort, P.; Ravikovitch, P. I.; De Jong, K. P.; Benjelloun,M.; Van Bavel, E.; Janssen, A. H.; Neimark, A. V.; Weckhuysen, B. M.;Vansant, E. F. J. Phys. Chem. B 2002, 106, 5873.

18 Botella, P.; Corma, A.; Lopez-Nieto, J. M.; Valencia, S.; Jacquot,R. J. Catal. 2000, 195, 161.

19 Arribas, M. A.; Martinez, A. Catal. 2001, 65, 117.

20 Y. H. Yue, A. Gedeon, J. L. Bonardet, N. Melosh, J. B. D’Espinose and J. Fraissard, Chem. Commun., 1999, 1967-1968.

21 Sadanobu Sumiya, Yasunori Oumi, Toshiya Uozumi and Tsuneji Sano, J. Mater. Chem., 2001, 11, 1111-1115. 
22 Schmidt-Winkel, P.; Lukens, W. W.; Zhao, D. Y.; Yang, P. D.;Chmelka, B. F.; Stucky, G. D. J. Am. Chem. Soc. 1999, 121, 254.

23 Zhao, D. Y.; Feng, J. L.; Huo, Q. S.; Melosh, N.; Fredrickson, G.H.; Chmelka, B. F.; Stucky, G. D. Science 1998, 279, 548;

24 Schmidt-Winkel, P.; Lukens, W. W.; Zhao, D. Y.; Yang, P. D.;Chmelka, B. F.; Stucky, G. D. J. Am. Chem. Soc. 1999, 121, 254.

25 Zhao, D. Y.; Feng, J. L.; Huo, Q. S.; Melosh, N.; Fredrickson, G.H.; Chmelka, B. F.; Stucky, G. D. Science 1998, 279, 548;

26 Van der Voort, P.; Ravikovitch, P. I.; De Jong, K. P.; Benjelloun,M.; Van Bavel, E.; Janssen, A. H.; Neimark, A. V.; Weckhuysen, B. M.;Vansant, E. F. J. Phys. Chem. B 2002, 106, 5873.

27 Y. H. Yue, A. Gedeon, J. L. Bonardet, N. Melosh, J. B. D'Espinose and J. Fraissard, Chem. Commun., 1999, 1967-1968.

28 Sadanobu Sumiya, Yasunori Oumi, Toshiya Uozumi and Tsuneji Sano. J. Mater. Chem., 2001, 11, 1111-1115.

29 Yousheng Tao, Kanoh Kutsumi Kaneko. J.Phys.Chem.B,107,10974-10976

30 Huang.J. Gong Li, Wu.S., Wang.H., Xing.L., Ke Song, Tonghao Wua and Qiubin Kan. J. Mater. Chem.. 2005, 15, 1055-1060

31 Sadanobu Sumiya, Yasunori Oumi, Toshiya Uozumi and Tsuneji Sano. J. Mater. Chem. 2001, 11, 1111-1115.

32 Liu, Y.; Pinnavaia, T. J.J .Am.Chem.Mater. 2002, 14, 3-5

33 S. Al-Khattaf. The Arabian Journal for Science and Enginnering.30,14 